\title{
Design, synthesis, chemical stability, packing, cyclic voltammetry, ionisation potential, and charge transport of [1]benzothieno[3,2- $b][1]$ benzothiophene derivatives
}

Christian Ruzié, ${ }^{a}$ Jolanta Karpinska, ${ }^{a}$ Anne Laurent, ${ }^{a}$ Lionel Sanguinet, ${ }^{b}$ Simon Hunter, ${ }^{c}$ Thomas D. Anthopoulos, ${ }^{c}$ Vincent Lemaur, ${ }^{d}$ Jérôme Cornil, ${ }^{d}$ Alan R. Kennedy, ${ }^{e}$ Oliver Fenwick, ${ }^{f, g}$ Paolo Samorì, ${ }^{f}$ Guillaume Schweicher, ${ }^{a, h}$ Basab Chattopadhyay, ${ }^{a}$ Yves Henri Geerts, ${ }^{a *}$

a) Laboratoire de Chimie des Polymères, Faculté des Sciences, Université Libre de Bruxelles (ULB), CP 206/1, Boulevard du Triomphe, 1050 Bruxelles, Belgium; e-mail ygeerts@ulb.ac.be.

b) LUNAM Université, MOLTECH-Anjou UMRCNRS 6200, Université d'Angers, 2 Bd Lavoisier, 49045 Angers Cedex, France.

c) Department of Physics and Centre for Plastic Electronics, Imperial College London, South Kensington, SW7 2AZ, United Kingdom

d) Service de Chimie des Matériaux Nouveaux, Université de Mons (UMons), Place du Parc 20, 7000 Mons, Belgium.

e) Department of Pure and Applied Chemistry, University of Strathclyde, 295 Cathedral Street, Glasgow G1 1XL, Scotland

f) ISIS \& icFRC, Université de Strasbourg \& CNRS, 8 allée Gaspard Monge, 67000, Strasbourg, France.

g) Current address: School of Engineering and Materials Science, Queen Mary University of London, Mile End Road, London E1 4NS, United Kingdom.

h) Current address: Optoelectronics Group, Cavendish Laboratory, University of Cambridge, JJ Thomson Avenue, Cambridge CB3 0HE, UK 
KEYWORDS: organic electronics, structure property relationship, benzothienobenzothiophene, organic field-effect transistors, ionization potential

\begin{abstract}
Five new molecular semiconductors that differ from dioctylbenzothienobenzothiophene, by the introduction of ether or thioether side chains, have been synthesized and obtained in good yields. Their availability in sufficient quantities has allowed investigation of their electrochemical behaviour in solution and their electronic properties in solid state. Both ether and thioether compounds oxidise rather easily in solution, but nevertheless, they exhibit rather high ionisation potentials. This is a consequence of their crystal structure. Dioctylthioetherbenzothienobenzothiophene is rather sensitive to oxidation and degrades easily in close to ambient conditions. Dioctylletherbenzothienobenzothiophene is more stable. Its charge carrier mobility remains however rather moderate, on the order of $0.5 \mathrm{~cm}^{2} / \mathrm{V}$.s, whereas that of dioctylbenzothienobenzothiophene reached $4 \mathrm{~cm}^{2} / \mathrm{V} . \mathrm{s}$, in the same conditions. The difference is explained by intrinsic factors as shown by a theoretical modelling.
\end{abstract}




\section{INTRODUCTION}

Charge carrier mobility, $\mu\left(\mathrm{cm}^{2} / \mathrm{V} . \mathrm{s}\right)$, is a key property of organic semiconductors (OSCs) that quantifies their ability to transport rapidly electrical charges, and thus, their usefulness as active materials in electronic devices. ${ }^{1-3}$ Most low molecular weight OSCs exhibit mobilities $\mu<1 \mathrm{~cm}^{2} / \mathrm{V}$.s, few display 1 $<\mu<10 \mathrm{~cm}^{2} / \mathrm{V} . \mathrm{s}$, and only very few show $\mu>10 \mathrm{~cm}^{2} / \mathrm{V} . \mathrm{s}^{4-12}$ In terms of molecular structures, rubrene, ${ }^{13-16}$ acenes, ${ }^{17}$ pentacene and anthradithiophene derivatives, ${ }^{18-20}$ benzothienobenzothiophenes (BTBTs), ${ }^{7,11,21-23}$ dinaphthothienothiophenes (DNTTs), ${ }^{12,24}$ benzothienonaphthodithiophenes (BBTNDTs), ${ }^{25}$ dibenzothiophenothienothiophenes (DBTTTs), ${ }^{9}$ dinaphthothiophene (DNTs), ${ }^{26}$ and dinaphthobenzodithiophenes (DNBDTs) ${ }^{8}$ qualify as best-performing OSCs for hole $\left(\mathrm{h}^{+}\right)$transport. A record value of $43 \mathrm{~cm}^{2} /$ V.s has been measured for dioctylbenzothienobenzothiophene 1a, at room temperature. ${ }^{27}$ Recently, a mobility value of $52 \mathrm{~cm}^{2} / \mathrm{V}$.s. has been reported for the same compound at 80 $\mathrm{K} .{ }^{4}$ Charge carrier mobility is a material property that depends evidently on the chemical structure, but not exclusively. The supramolecular order spanning several lengthscales, i.e., from $\AA$ to $100 \mu \mathrm{m}$, and the dimensionality of charge transport are also of paramount importance. ${ }^{28}$ Charge carrier mobility is generally measured in field-effect transistors but in large diversity of experimental conditions that seriously complicates benchmark. Moreover, very high charge carrier mobility values could result from unintentional experimental errors or data misinterpretation as pointed out by Chen et al. ${ }^{29}$ If the common sense principle that measurements under comparable conditions must have been reproduced by at least two independent groups is applied, then a current upper limit of $20 \mathrm{~cm}^{2} / \mathrm{V} . \mathrm{s}$, measured with field effect transistors at room temperature, is commonly admitted and higher values are awaiting to be confirmed. ${ }^{10}$ Importantly, charge carrier mobility is increasingly measured by other methods such as terahertz spectroscopy, ${ }^{30}$ field-induced time-resolved microwave conductivity, ${ }^{31}$ field-induced electron spin resonance, $^{32-34}$ and quantum Hall effect. ${ }^{35,36}$

A second important evaluation criterion of p-type OSCs is their first ionization potential, IP (eV), that corresponds to the energy required to remove an electron from the highest occupied molecular orbital (HOMO). The IP of organic semiconductors must match the work function, $\phi(\mathrm{eV})$, of electrodes to allow for easy charge injection and collection. ${ }^{37,38}$ It is generally admitted that IP values are mostly determined by the chemical structure and not so much by supramolecular order. ${ }^{39}$ However, this assumption is often not valid because it omits the additional electronic contribution of packing inherent to crystalline OSCs, as pointed out by recent theoretical ${ }^{40-42}$ and experimental works. ${ }^{43,44}$ In addition, it has also been evidenced that the ionization potential depends on molecular orientation. ${ }^{45}$

A third evaluation criterion is the chemical stability of OSCs that again depends on molecular structure and supramolecular order. Pentacene, that is the most studied OSCs, is dramatically unstable in dilute solution. It photo-oxidizes rapidly into pentacenequinone upon exposure to light and oxygen. ${ }^{46,47}$ However, the same pentacene is chemically stable in thin films and has abundantly been used as an 
efficient semiconductor in organic field-effect transistors (OFETs). ${ }^{1,2}$ Note that the chemical stability issue can neither be separated from that of purity, since traces of side products, acids, reagents, or catalyst residues can trigger and/or accelerate chemical degradation, nor from phase behaviour, since the diffusion of oxygen is facilitated in liquid and liquid crystalline phases in comparison to crystal phases. An indirect evidence of that is the detrimental effect that thermal annealing has on charge transport of some OSCs. $^{48,49}$

Among the high mobility hole carriers thienoacene-based organic semiconductors are likely the most promising ones, because of their ease of synthesis and performances. They are currently under intense investigations to link chemical structure and crystal packing with electronic properties. But structure correlates rather moderately with properties, as evidenced recently for a large survey of systems. ${ }^{50}$ The reason is likely that structural information are mostly available at nanometer scale whereas electronic properties are measured at macroscopic scales. ${ }^{10,51}$ This context clearly calls for new physical studies but also for the synthesis of homologous series of OSCs.

In this paper, we address these three criteria at molecular and supramolecular levels with the selected BTBT derivatives, depicted in Figure 1. Specifically, we have used the well-known 2,7dioctyl[1]benzothieno[3,2-b][1]benzothiophene $\mathbf{1 a}$ as a reference point to design 2,7dioctylether[1]benzothieno[3,2-b][1]benzothiophene $\mathbf{2 a},^{52-54}$ and 2,7-dithiooctyl[1]benzothieno [3,2$b][1]$ benzothiophene $\mathbf{3 a}$ in an attempt to decrease the IP to 5.1-3 eV, i.e. to a value closer to the Fermi level of air-exposed solvent cleaned gold, $\phi_{A u} \approx 4.7-4.9 \mathrm{eV} .{ }^{55}$ The comparison of the electronic properties of compounds 2a-c and 3a, b serves to probe the effect of packing. Known compounds 4-8 have been involved as well for the sake of comparison in the framework of the electrochemical study. This work provides fine structure property relationships for BTBT derivatives substituted at 2, 7 positions. 


\section{RESULTS \& DISCUSSION}

\section{Design and synthesis}

The design of the molecules is rather simple. In a first step, heteroatoms have been introduced between the aromatic core and alkyl side chains since they are known from the field of liquid crystals to considerably modify the thermotropic behaviour. ${ }^{56}$ Moreover, oxygen and sulphur are electron mesomer donor. Lower oxidation potentials and ionization energies are thus anticipated. In a second step, the chemical structure of side chains has been varied to tune both thermotropic behavior and crystal structure. In particular, branching and the presence of a fluorinated segment should prevent chain interdigitation.

The 2,7-dialkyloxy-[1]benzothieno[3,2-b][1]benzothiophenes were synthetized by modified copper-mediated Ullmann ether synthesis, as described by Buchwald et al. ${ }^{57}$ Starting from 2,7-diiodo[1]benzothieno[3,2-b][1]benzothiophene $(\mathbf{9}),{ }^{58}$ a coupling reaction with a catalyst system consisting of copper(I) iodide, 1,10-phenanthroline, and cesium carbonate in respectively 1-octanol, 5-methyl-1hexanol, and 7,7,8,8,8-pentafluoro-1-octanol afforded 2,7-dialkyloxy-[1]benzothieno[3,2b][1]benzothiophenes $\mathbf{2 a}, \mathbf{2 b}$, and $\mathbf{2 c}$ in $70 \%, 43 \%$ and $48 \%$ yield, respectively (Table 1). ${ }^{53}$

The 2,7-dialkylthio-[1]benzothieno[3,2-b][1] benzothiophenes were synthetized by two different pathways (Scheme 1). As for 2,7-dialkyloxy-[1]benzothieno[3,2-b][1]benzothiophenes, reaction of 9 with a catalytic system consisting of copper(I) iodide, 1,10-phenanthroline, and cesium carbonate in octanethiol afforded 3a in $66 \%$ yield. The second pathway entailed the synthesis of $\mathbf{3 b}$. Starting from 2,7-dibromo-[1]benzothieno[3,2-b][1]benzothiophene $(\mathbf{1 0}),{ }^{59}$ reaction with a large excess of sodium thiomethylate ${ }^{60}$ in DMA at $150{ }^{\circ} \mathrm{C}^{61}$ gave the free thiophenol 11 in $84 \%$ yield. Subsequent alkylation with 1-bromo-5-methylhexane in $\mathrm{DMF}^{62}$ led to $\mathbf{3 b}$ in $58 \%$ yield. Two different synthetic routes have been chosen to obtain $\mathbf{3 a}$ and $\mathbf{3 b}$, to document the chemistry of BTBTs. It can be concluded that the target compounds are readily accessible in good yield and in sufficiently large amount to allow the investigation of their properties in solution and in solid state.

\section{Electrochemistry}

The electrochemical properties of BTBT $\mathbf{8}$ and of the substituted BTBT derivatives 1a, 2a, 3a, and 4-7 were investigated, in dichloromethane, by cyclic voltammetry (CV). Their electrochemical data are collected in Table 2 together with those of unsubstituted BTBT, for comparison. Cyclic voltammetry curves are given in Supporting Information. All BTBT derivatives investigated in this study present at least one reversible oxidation process which produces radical cation species. However, the substitution of the BTBT core at positions 2 and 7 by electron donating groups such as alkoxy, thioalkyl or amino group, lead to a second oxidation process at higher potential corresponding to the formation of dication species. Unfortunately, this second process is only perfectly reversible for compound $\mathbf{2 a}$. 
As expected, the redox potential corresponding to the formation of radical cation is quite sensitive to the substituent groups on BTBT core. In fact, the insertion of an electron donating group such as thioalkyl, alkoxy or simple alkyl is anticipated to lead to a negative shift of the redox potential in comparison with unsubstitued BTBT. In this context, it is not surprising to observe a $\sim 200 \mathrm{mV}$ negative shift of the first oxidation potential by the introduction of two octyl chains in agreement with reported values for 2,7dialkyl-[1]benzothieno[3,2-b][1]benzothiophenes. ${ }^{63}$

As we can see on Table 2, the variation of the first oxidation potential with the nature of the substituent follows our expectations. In fact, the introduction of electron donating groups such as alkyl, alkyloxy, thioalkyl or amino substituents induce a negative shift up to $\sim 700 \mathrm{mV}$. Conversely, the introduction of some electron withdrawing groups such as nitro substituents, induces a positive shift up to $\sim 400 \mathrm{mV}$.

In order to study the influence of the substitution on one reactivity, the Hammett linear free energy relationship is generally used. The comparison of the rate constants or the equilibrium constants of a reaction with substituted $\left(\mathrm{k}_{\mathrm{x}}\right)$ and unsubstitued compounds $\left(\mathrm{k}_{\mathrm{H}}\right)$ allows respectively the determination of a variation in the free energies or activation energies of this reaction as function of two parameters: the reaction constant, $\rho$, which reflects the susceptibility of the reaction to the substitution, and the substituent constant, $\sigma$, which depends solely on the nature and position of the substituent. ${ }^{64}$

$$
\log \frac{k_{X}}{k_{H}}=\rho \sigma
$$

Concerning redox processes, previous studies have demonstrated that a difference of free energy induces a variation of the formal potential, and by consequence can be expressed from the reaction and substituent constant by the following relation where $\rho$ and $\sigma$ are respectively the reaction and the substituent constants: ${ }^{65}$

$$
\Delta \mathrm{E}=\mathrm{E}_{H}^{0}-\mathrm{E}_{X}^{0}=\left(\frac{2.3 \mathrm{RT}}{n F}\right) \log \frac{k_{X}}{k_{H}}=\left(\frac{2.3 \mathrm{RT}}{n F}\right) \rho \sigma
$$

In Hammett plots, the redox potentials for the formation of radical cation and anion are correlated with Brown coefficients, i.e. the electrophilic constant, $\sigma^{+}$, and the nucleophilic constant, $\sigma^{-}$, respectively. ${ }^{66}$ Specifically, the first oxidation potential and the substituent $\sigma^{+}$correlate well for several thiophene-based aromatic molecules such as terthiophenes and quatertiophenes. ${ }^{67}$ As shown in Figure 2, the first oxidation potential of BTBT derivatives 1a, 2a, 3a, 4-8 follows a linear relationship with respect to the electrophilic substituent constants $\sigma_{p}^{+}$for the para substitution. ${ }^{66}$ The correlation of first oxidation potentials with $\sigma_{p}^{+}$ 
shows that there is a resonance effect enhanced by substituents. As a consequence, the first oxidation process implies a mechanism where the positive charge is stabilized by mesomeric effects. In conclusion, it is observed that ether and thioether functions ease the oxidation of the BTBT core. The subsequent question, that is discussed in the next section, is to know if the easier oxidation in solution is reflected by a smaller IP in solid state?

\section{Photoelectron spectroscopy}

IP has been measured for compounds 1a, 2a-c, and 3a,b, by photoelectron spectroscopy in air (PESA) for powder, drop-casted films, and spin-coated films. Results are collected in Table 3. IP of 1a has previously been measured by PESA and has been found to have a value of $5.3 \mathrm{eV} .{ }^{49}$ For the sake of completeness, we have also measured it and obtained comparable values. No specific trends are observed for IP as a function of sample preparation. For $\mathbf{2 a}$ and $\mathbf{3 b}$, films give rise to smaller IPs than powder, whereas the reverse is observed for 3a. Here it must be noted that 2a exhibits a substrate-induced polymorph with a rather different crystal structure than the bulk phase. ${ }^{52,54}$ It is, however, not possible to correlate the lower IP of spin-coated films with the metastable substrate-induced polymorph, since the depth sensitivity of PESA is $<10 \mathrm{~nm}$ and thus much thicker drop-cast films show a comparable IP to the thinner spin coated films. No significant differences are observed between samples for $\mathbf{2 b , c}$. Table 2 shows that compounds $\mathbf{2 a}$ and 3a are easier to oxidize than the reference compound 1a, by 0.317 and $0.295 \mathrm{~V}$, respectively in solution. On this basis, it was anticipated that the IP of 2a-c and 3a,b would be smaller than that of $\mathbf{1 a}$ by roughly $+0.3 \mathrm{eV}$. To the contrary, compounds $\mathbf{2 a - c}$ and $\mathbf{3 a}, \mathbf{b}$ exhibit all a larger IP by up to $0.64 \mathrm{eV}$. To shed light into this unexpected behaviour, the ionization potentials of 1a and $2 \mathbf{a}$ have been calculated at the semi-empirical Hartree-Fock MNDO level (see Experimental section) for isolated molecules and for small clusters. The theoretical predictions on isolated molecules confirm the $\mathrm{CV}$ data that $\mathbf{2 a}$ is easier to oxidize than $\mathbf{1 a}$ by $0.32 \mathrm{eV}$ (calculated IP is $7.83 \mathrm{eV}$ for $\mathbf{1 a}$ and $7.51 \mathrm{eV}$ for 2a).Interestingly, when considering the charged molecules within small neutral clusters, i.e., when including polarization effects, the situation is drastically different and the calculated ionization potential of $2 \mathbf{a}$ becomes larger than $\mathbf{1 a}(7.58 \mathrm{eV}$ vs $7.29 \mathrm{eV}$ for $\mathbf{2 a}$ and 1a, respectively), in qualitative agreement with the PESA data. This huge IP difference between isolated molecules and small clusters highlights the importance of considering intermolecular interactions in the evaluation of the ionization potentials since crystal packing plays a significant role on the stabilization of charges by electrostatic and polarization effects in molecular semiconductors and hence on the ease of charge injection from electrodes.

\section{Crystal structures}

Since crystal packing considerably modifies the first ionisation potential, this section explores how two modifications of the molecular structures, i.e. the presence of a connecting heteroatom between 
the aromatic BTBT core and side chains, and the nature of the side chain, impact the crystal structures. Crystallographic data of compounds 1a, 2a-c and 3b* (vide infra) are collected in Table 4 and important features of the crystal packing are discussed in the following section. The crystal structure of compound 1a has previously been reported. ${ }^{68}$ In the past few years, compound 1a has emerged as the most studied and one of the best performing organic semiconductors. ${ }^{10}$ Hence, it is often considered as a reference structure and it is discussed here for the sake of comparison. Compound 1a essentially exhibits a "layer by layer" organization with the molecules in each layer packed in a herringbone motif which is known to facilitate two dimensional charge transport desirable for thin film transistors. For the sake of simplicity the crystal structures of $\mathbf{2 a - c}$ are first discussed together with the following sections discussing the crystallisation behaviour of $\mathbf{3 a}, \mathbf{b}$ and finally the structure of $\mathbf{3} \mathbf{b}^{*}$. Molecular views of all compounds are given in Figure 3. Compounds $\mathbf{2 a}$ and $2 \mathbf{b}$ crystallize in triclinic and orthorhombic unit cells, respectively, with one molecule in the asymmetric unit $\left(Z^{\prime}=1\right)$, whereas $\mathbf{1 a}, \mathbf{2} \mathbf{c}$ and $\mathbf{3} \mathbf{b}^{*}$ crystallize in monoclinic unit cells with $Z^{\prime}=0.5$. Compound $\mathbf{2 a}$ is the only example where the side chains exhibit interdigitation, as shown in Figure $4 .^{54}$ The aromatic cores of the $\mathbf{2 a}$ molecules are aligned in a co-facial manner with the BTBT cores interlinked via $\pi \ldots \pi$ interactions to produce parallel ladder arrangement (Figure 4). The individual ladders are connected via C-H... $\pi$ bonding to form a two dimensional network. The crystal structure of compound $\mathbf{2 a}$ is the same as the structure observed for the room temperature phase of the bulk material. For compounds $\mathbf{2 b}$ and $2 \mathbf{c}$, the side chains extend away from the aromatic core of the molecule; however, they do not interdigitate, as found in the case of compound 2a. They exhibit lamellar packing of molecules with each layer arranged in a herringbone fashion, as observed in compound 1a and other BTBT based molecules. ${ }^{49,69}$ The 2D-herringbone structure is stabilised by C-H... $\pi$ interactions (Table 5, Figure 5). The conjugated BTBT-cores in $\mathbf{2 b}$ and $\mathbf{2 c}$ make a herringbone angle of $\sim 54^{\circ}$ and $68^{\circ}$, respectively with respect to its nearest neighbor. Additionally in $2 \mathbf{c}$, the aromatic cores of the molecules are arranged in a slipped stack manner in the $b$ direction, forming $\pi$ stacked columns that are related to the one another by the glide plane and separated by a distance equivalent to $c / 2(5.69 \AA)$. The ring centroid distance and the slippage distance of one molecule relative to another in one stack column were calculated to be $5.649 \AA$ and $4.687 \AA$ respectively. In $\mathbf{2 b}$, however, there are no such $\pi \ldots \pi$ interactions.

Despite several attempts, it was not possible to grow single crystals of compound 3a with sufficient quality to allow the elucidation of its crystal structure. Sublimation in a temperature gradient and sublimation on a cold finger does not produce crystalline material. Solvent-based methods such as slow evaporation from a single solvent or mixtures and vapour diffusion gave multi-crystalline structures and twined crystals with curved edges. After several trials, compound 3a turned partially yellow, indicating slow sample degradation. HPLC analysis of samples before and after crystallization experiments shows a significant increase in impurities upon sample decomposition (see Figure S50). 
These impurities probably prevent compound 3a from growing as single crystals. Compound $\mathbf{3 b}$ has been synthesized and its molecular structure has unambiguously been established by NMR spectroscopy and mass spectrometry. The following solvents were employed during the process of growing single crystals of compound $\mathbf{3 b}$ by slow evaporation at RT: hexane, toluene, $p$-xylene, dichloromethane and chloroform. The initial attempts resulted in the formation of non-crystalline structures. However, after several recrystallisation trials using the same material, plate-shaped crystals were obtained. These crystals were analysed by single crystal XRD; however, they were not crystals of compound $\mathbf{3 b}$ but the oxidised form 3b* (Scheme 2). Due to the molecular geometry of the $\mathrm{SO}_{2}$ motif, compound $\mathbf{3 b}$; is the only example where side chains do not extend away from the centre of the molecule. Instead, the side chains are orientated nearly perpendicular to the plane of the aromatic core (Figure 1). As it is the case for compounds 1a, $\mathbf{2 b}$ and $\mathbf{2 c}$, compound $\mathbf{3 b}$ * displays a 2D herringbone arrangement, the herringbone angle between the nearest neighbour BTBT cores being $64^{\circ}$. Due to the presence of $\mathrm{SO}_{2}$ groups, the crystal packing in $\mathbf{3} \mathbf{b}^{*}$ is governed by C-H...O hydrogen bonds (Table 5). Similarly to compound 2c, the molecules of compound $3 \mathbf{b}^{*}$ form $\pi$ stacked columns along the $b$ direction with an inter-columnar distance of c/2 (5.12 $\AA$ ) and are related to each other by a glide plane. The distance between the ring centroids of the molecules within a column is equal to $5.417 \AA$ and the slippage between molecules within a stacked column $5.567 \AA$.

To further investigate quantitatively and visually these intermolecular interactions, the Hirshfeld surfaces $^{70}$ of $\mathbf{2} \mathbf{a}-\mathbf{c}$ and $\mathbf{3} \mathbf{b}^{*}$ were calculated and are illustrated in Figure 6, showing surfaces that have been mapped over a $d_{\text {norm }}$ range of 0.15 to $1.5 \AA$. Due to the varying number and types of the substituents, they are not directly comparable across the compounds, but they offer some insights into the effect of the different substituents on the BTBT backbone. The dominant interactions can be seen in the Hirshfeld surfaces as the bright red areas which correspond to the $\mathrm{C}-\mathrm{H} \cdots \pi$ hydrogen interactions in $\mathbf{2 a - c}$ and $\mathrm{C}$ $\mathrm{H} \cdots \mathrm{O}$ hydrogen bonds in $3 \mathbf{b}^{*}$. A look at the 2D fingerprint plots (Figure 6) clearly reveals that the packing environments are completely different depending on the nature of side-chain modifications. The C-H $\cdots \pi$ hydrogen bonds in $2 \mathbf{a}$ appear as two pairs of wings of almost equal lengths $\left(d_{\mathrm{i}}, d_{\mathrm{e}}\right)$ in the regions between (1.7 $\mathrm{A}, 1.1 \AA$ ) and (1.1 $\mathrm{A}, 1.7 \AA$ ), marked as a and a* in Figure 6. Similarly in $\mathbf{2 b}, \mathbf{c}$ and $\mathbf{3 b}$, they are marked as $\mathrm{b} / \mathrm{b}^{*}, \mathrm{~d} / \mathrm{d}^{*}$ and $\mathrm{f} / \mathrm{f}^{*}$ respectively. In $\mathbf{2 b}$ a pair of wings appearing in the $\left(d_{\mathrm{i}}, d_{\mathrm{e}}\right)$ regions between $(2.0 \AA, 1.1 \AA)$ and $(1.0 \AA, 2.0 \AA)$ in the fingerprint plots marked as b/b* is also a consequence of the $\mathrm{C}-\mathrm{H} \cdots \pi$ interactions. Additionally in $\mathbf{3} \mathbf{b}^{*}$, prominent pairs of sharp spikes of almost equal length in the $\left(d_{\mathrm{i}}, d_{\mathrm{e}}\right)$ regions between $(1.4 \AA, 1.0 \AA)$ and $(1.0 \AA, 1.4 \AA)$, marked as e/e* are characteristics of nearly equal $\mathrm{C}$ (donor)...O(acceptor) distances. The relative contributions of the different intermolecular interactions to the Hirshfeld surface area are depicted in Figure 7 for compounds 1a, 2a-c and 3b*. The quantitative analysis clearly shows that $\mathrm{H}$...H contacts are dominant contributors to the Hirshfeld surface area, revealing the role that alkyl chains have on the overall crystal packing. The contribution of the 
$\mathrm{H}$...H is as high as $79.6 \%$ in $\mathbf{1 a}$ and decreases with the number of $\mathrm{H}$-atoms in the molecule. In $\mathbf{2 c}$, the corresponding value is only $32.6 \%$ but it is compensated by the F...F and the F...H contacts which contribute by about $49 \%$ to the corresponding Hirshfeld surface. The $\mathrm{C} \cdots \mathrm{H}$ contacts corresponding to $\mathrm{C}$ $\mathrm{H} \cdots \pi$ interactions vary marginally, from $11.6 \%$ in $\mathbf{1 a}$ to $19.1 \%$ in $\mathbf{2 a}$ despite the fact that the crystal packing in 1a, $\mathbf{2 b}, \mathbf{c}$ and $3 \mathbf{b}^{*}$ corresponds to a $\mathrm{C}-\mathrm{H} \ldots \pi$ mediated herringbone structure whereas the crystal packing in 2a is essentially a co-facial $2 \mathrm{D}$ structure stabilized by $\pi \ldots \pi$ and $\mathrm{C}-\mathrm{H} \ldots \pi$ hydrogen bonds. The presence of $\mathrm{C}-\mathrm{H} \ldots \mathrm{O}$ hydrogen bonds in $\mathbf{3} \mathbf{b}^{*}$ is reflected through the contribution of $\mathrm{O}$...H contacts, which is $21.8 \%$ in $\mathbf{3} \mathbf{b}^{*}$ while in $\mathbf{2 a - c}$ the corresponding value is $3.2-4.7 \%$. The most interesting observation is that, in spite of the presence of C-H...O interactions in $\mathbf{3} \mathbf{b}^{*}$, it replicates the herringbonelike packing of $\mathbf{1 a}, \mathbf{2} \mathbf{b}$ and $\mathbf{2 c}$ whereas $\mathbf{2 a}$ has a columnar packing.

\section{Thermal behaviour}

Thermogravimetric analysis (TGA) and differential scanning calorimetry (DSC) were used to assess the stability and obtain information on phase transitions of compounds 1, 2a-c, and 3a,b. Table 6 shows weight loss onset temperatures and transition temperatures with the associated standard enthalpies. TGA and DSC traces are given in the supporting information (Figures S28-S39). Weight loss measured by TGA encompasses two phenomena. On the one hand, some compounds degrade and their fragments volatilise. On the other hand, some other compounds sublime before degradation. The tendency to sublimation depends on the molecular weight of the compounds but also on their intermolecular interactions and thus on their crystalline or liquid crystalline phases. It is therefore not particularly meaningful to compare the $\mathrm{T}_{\text {onset }}$ values of compounds 1a, 2a-c, and 3a,b. $\mathrm{T}_{\text {onset }}$ only indicates the temperature up to which DSC traces can be recorded. It is noteworthy to indicate that both TGA and DSC analyses have been performed under inert atmosphere.

Upon heating, compound 1a exhibits a crystalline and smectic A phase before reaching the melt state as previously reported. ${ }^{68}$ Compound $2 \mathbf{a}$ shows two phase transitions before melting at $173{ }^{\circ} \mathrm{C}$ (Figure 8). Thermal transitions at $90.7{ }^{\circ} \mathrm{C}$ and at $159.3{ }^{\circ} \mathrm{C}$ were assigned to the transition to another crystalline phase $\left(\mathrm{Cr}_{1}-\mathrm{Cr}_{2}\right)$ and to a liquid crystalline phase $\left(\mathrm{Cr}_{2}-\mathrm{LC}\right)$, as indicated by the values of transition enthalpies in Table $6 .^{52}$ New phases have also been identified by the XRD temperaturedependent measurements (Figure S41) and the fan shaped texture of LC phase has been observed at 165 ${ }^{\circ} \mathrm{C}$ by POM (Figure S45). Both DSC and temperature-dependent XRD measurements confirm that the structure of the room temperature (RT) phase is the same before and after the thermal treatment and corresponds to the solved crystal structure presented above. This was demonstrated by comparison of the calculated XRD pattern of the single crystal phase and the experimental XRD pattern of the bulk phase. XRD patterns were also collected at various temperatures according to the phase transitions observed by the DSC, revealing the transition to the high temperature crystalline phase $\left(\mathrm{Cr}_{2}\right)$ (Figure S40a) that differs 
from the substrate-induced polymorph reported by Jones et al. ${ }^{52}$ Furthermore, the powder XRD pattern of compound 2a collected at $165^{\circ} \mathrm{C}$ shows the presence of only three diffraction peaks (Figure S40b), which correspond to the 001,002 and 003 planes with a calculated d spacing of $31.07 \AA$, $15.49 \AA$, and $10.29 \AA$, respectively, pointing to a lamella packing. The d spacing, which agrees with the $c$ cell parameter, is characteristic for the LC phase which was identified as the smectic $C$ phase $\left(S_{m} C\right)$ with a calculated tilt angle of $23.6^{\circ}$, considering that the length of $\mathbf{2 a}$ is $\sim 33.9 \AA$ for a fully extended conformation. Compound $\mathbf{2 b}$ shows only one transition before melting at $172{ }^{\circ} \mathrm{C}$ which was identified as a transition to a high temperature polymorph $\left(\mathrm{Cr}_{1}-\mathrm{Cr}_{2}\right)$ as shown by the enthalpy value. This solid-solid transition is reversible upon cooling of the sample indicating enantiotropic behaviour of the two polymorphs. Powder XRD patterns of the RT and HT phases are given in Figure S41. Compound 2c, similarly to 2a, exhibits two phase transitions before melting, but melts at a slightly higher temperature: $205.7{ }^{\circ} \mathrm{C}$ (Figure 8). Based on the enthalpy values in Table $\mathrm{X}$, the transition at $134{ }^{\circ} \mathrm{C}$ was identified as $\mathrm{Cr}_{1}-\mathrm{Cr}_{2}$ and at $148{ }^{\circ} \mathrm{C}$ as $\mathrm{Cr}_{2}$-LC. Compound $\mathbf{2 c}$ also exhibits an enantiotropic behaviour as the solid-solid conversion is a reversible process, also observed in cooling step (Figure 8). These phases were also observed using the POM and temperature-dependent XRD measurements (Figures S42 and S45). A comparison of the calculated powder XRD pattern of the solved crystal structure and experimental patterns of the RT and HT phases shows that the single crystal phase does not match any of the phases observed in the bulk material. Figure S42 presents the powder XRD pattern showing diffraction from first order reflections of a LC phase of compound $2 \mathrm{c}$ collected at $170{ }^{\circ} \mathrm{C}$. The texture of the LC phase was identified as $\mathrm{S}_{\mathrm{m}} \mathrm{C}$. A tilt angle of $23.9^{\circ}$ has been calculated from the d spacing of $31.17 \AA$, considering that the length of $2 \mathrm{c}$ is $34.1 \AA$ for a fully extended conformation. Compound 3a also exhibits polymorphism with $\mathrm{Cr}_{1}-\mathrm{Cr}_{2}$ transition occurring at $109{ }^{\circ} \mathrm{C}$ for the first heating run (Figure S37). Upon further heating, the $\mathrm{Cr}_{2}$ phase melts at $162.1{ }^{\circ} \mathrm{C}$. The second heating run exhibits only the melting at $161.8^{\circ} \mathrm{C}$. For compound $\mathbf{3 b}$, polymorphism was observed close to the melting point. The initial scan performed with a heating rate of $10{ }^{\circ} \mathrm{C} / \mathrm{min}$ shows the presence of a shoulder in the melting peak. To obtain better resolution, the heating rate was reduced to $1{ }^{\circ} \mathrm{C} / \mathrm{min}$; however, this did not improve peak separation (Figure S39). The phase behaviour upon temperature variation has not been further investigated given the tendency of these compounds to oxidize in solution, as evidenced by HPLC traces (Figures S50 and S51).

\section{Charge transport}

Bottom-gate, top-contact (BG-TC) OTFTs were fabricated using molecules 1a, 2a, and 3a. Compounds $\mathbf{2 b}, \mathbf{c}$ have not been investigated because of their too high IP precluding an easy charge injection. Results are collected in Table 7. All three molecules exhibited a p-type semiconducting behaviour with the performance closely linked to the level of film crystallinity that was achieved and observed using polarized optical microscopy (POM). Molecule 1a formed large, extended crystals that spanned the 
transistor channel. As such, the device performance was exceedingly high (Figure 10), exhibiting a typical saturation mobility of $4 \mathrm{~cm}^{2} / \mathrm{Vs}$ and a subthreshold slope of $1.5 \mathrm{~V} / \mathrm{dec}$. Molecule $2 \mathrm{a}$ was also found to form crystals spanning the transistor channel; however, the mottled appearance of the crystals, as imaged by POM (Figure 9), suggests that the molecular packing is less uniform than in molecule 1a. Consequently, a typical saturation mobility of $\sim 0.5 \mathrm{~cm}^{2} / \mathrm{Vs}$ and subthreshold slope of close to $5 \mathrm{~V} / \mathrm{dec}$ is observed (Figure 11). In spite of the lower performance, the device suffered less from charge injection problems from the Au electrodes compared to molecule 1a. The reason for that is undetermined but could be related to a local change of structure. Molecule 3a on the other hand was found to form poor quality polycrystalline thin films that resulted into low performance transistors exhibiting a high $\mathrm{V}_{\mathrm{T}}$ of $-50 \mathrm{~V}$ and hole mobilities on the order of $10^{-4} \mathrm{~cm}^{2} / \mathrm{Vs}$ (Figures 9 and 12). The poor quality of the interface between the semiconductor and the $\mathrm{SiO}_{2}$ dielectric is believed to be the predominant reason for the observed poor transistor performance. We confirmed this by fabricating top gate devices which exhibited reduced threshold voltage and hole mobilities up to $0.05 \mathrm{~cm}^{2} / \mathrm{Vs}$, albeit with increased hysteresis in the transfer characteristics. However, we cannot exclude a negative impact on charge transport of the poor chemical stability.

\section{Theoretical modelling}

In order to probe whether the lower hole mobility measured for $\mathbf{2 a}$ has an intrinsic origin or is only due to a less uniform packing, as suggested by POM images, the hole transport properties of 1a and 2a have been investigated at the theoretical level, considering in the first approximation a hopping transport regime (see Experimental section). The internal reorganization energies associated to positive polarons are larger for $\mathbf{2 a}$ (360 $\mathrm{meV}$ and $245 \mathrm{meV}$ for $\mathbf{2 a}$ and $\mathbf{1 a}$, respectively, in agreement with earlier studies) ${ }^{71,72}$ and hence detrimental for hole transport. This evolution is consistent with a previous work pointing to a systematic increase in the reorganization energies of discotic conjugated compounds upon introduction of oxygen atoms between the conjugated core and alkyl chains. ${ }^{73,74}$ The HOMO transfer integrals in 1a are large along the $a$ crystallographic axis $(40 \mathrm{meV})$, much smaller in the herringbone directions (12 meV) and negligible along the $b$ crystallographic axis (see Figure 13). This translates into an anisotropic behaviour of the charge transport in the $a b$ plane with a maximal calculated hole mobility of $1.37 \mathrm{~cm}^{2} / \mathrm{Vs}$ and an anisotropic ratio of 13 . The order of magnitude of the calculated hole mobilities are consistent with the measured mobilities as well as with previous theoretical data obtained in the hopping regime limit. ${ }^{71}$ Note also that higher hole mobilities have been reported for 1 a $\left(\sim 36 \mathrm{~cm}^{2} / \mathrm{Vs}\right)^{72}$ when considering a band model, as expected. In light of the results provided by the two extreme theoretical models, the experimental mobilities suggest that charge transport occurs rather through a hopping regime than a band regime hindered by the presence of structural defects since POM images reveal large crystals. The HOMO transfer integrals in $\mathbf{2 a}$ are also large $(40 \mathrm{meV})$ and negligible along the a and $\mathrm{b}$ 
crystallographic axes, respectively. In contrast to the herringbone packing of $\mathbf{1 a}$ which gives rise to moderate transfer integrals $(12 \mathrm{meV})$ along the herringbone direction, the other pathways for charge transport in $\mathbf{2 a}$ are rather inefficient (never exceeding $5 \mathrm{meV}$ ) since they involve parallel molecules translated along the c axis, which therefore does not favour large overlap between their HOMO orbitals. In terms of hole mobility, this translates into a maximal calculated hole mobility of $0.65 \mathrm{~cm}^{2} / \mathrm{Vs}$ and an anisotropic ratio of 92. Such a high ratio implies that hole transport in $\mathbf{2 a}$ mostly takes place along one direction. Interestingly, the limited upper value for the hole mobility in $\mathbf{2 a}$ is mainly driven by its large reorganization energy; if 2a shared the same value of reorganization energy as 1a, it would hypothetically reach a theoretical value of $1.18 \mathrm{~cm}^{2} / \mathrm{Vs}$ which is comparable to 1a. Putting all this together, our theoretical predictions suggest that the lower measured hole mobility in 2a can be explained from intrinsic reasons without referring necessarily to less uniform crystals in the transistor channel.

\section{CONCLUSIONS}

Five novel molecular semiconductors, compounds $\mathbf{2 a - c}$ and 3a,b, have been synthesized. They differ structurally from the well-known 1a, by the introduction of a oxygen or a sulphur atom between the aromatic BTBT core and the aliphatic side chains. In solution, compounds $\mathbf{2 a}$ and $\mathbf{3 a}$ are easier to oxidize than 1a. But in solid state, the ease of oxidation of $\mathbf{2 a}$ and $\mathbf{3 a}$ is cancelled out by packing effects that lead to high IP. The effect of packing is further documented by the comparison of 2a-c that by structure of their alkyl side chains. 1a exhibits a rather high charge carrier mobility, $\mu_{\text {saturation }}=4 \mathrm{~cm}^{2} /$ V.s, whereas $2 \mathbf{a}$ and 3a show charge carrier mobility values that are roughly one and two order of magnitudes lower, respectively. The moderate charge carrier mobility of $\mathbf{2 a}$ originates from its molecular and crystal structures. The poor performances of 3a are likely related to its instability towards close to ambient conditions. It is concluded that the functionalization of the BTBT core by ether and thioether side chains is not a good molecular design element to reach high charge carrier mobility values but it has proven to be valuable to demonstrate the effect of packing on electronic properties. 


\section{EXPERIMENTAL SECTION}

Reagents, solvents, and known compounds: All reagents and solvents were purchased from Aldrich, Alfa Aesar, or Acros. 7,7,8,8,8-Pentafluorooctan-1-ol was purchased from Manchester Organics. 2,7dioctyl-[1]benzothieno[3,2- $b][1]$ benzothiophene (1) was prepared following a literature procedure. ${ }^{75}$ The reagents 2,7-diiodo-[1]benzothieno[3,2-b][1]benzothiophene $(\mathbf{9}),{ }^{58}$ 2,7-dibromo-[1]benzothieno[3,2$b][1]$ benzothiophene $(\mathbf{1 0}),{ }^{59}$ and sodium thiomethylate ${ }^{60}$ were synthesized according to known procedures. Compounds 4-8 that have served for electrochemical studies have also been prepared according to literatures. ${ }^{58,76-77}$

Synthesis of 2,7-dioctyloxy-[1]benzothieno[3,2,b]benzothiophene (2a): A mixture of 2,7-diiodo[1]benzothieno[3,2-b][1]benzothiophene (6) (984 mg, $2 \mathrm{mmol})$, CuI (152 mg, $0.8 \mathrm{mmol}), 1,10-$ phenanthroline $(317 \mathrm{mg}, 1.6 \mathrm{mmol})$, and $\mathrm{Cs}_{2} \mathrm{CO}_{3}(2.61 \mathrm{~g}, 8 \mathrm{mmol})$ in 1-octanol $(50 \mathrm{~mL})$ in a Schlenk flask was degassed by 2 "freeze-pump-thaw" cycles. The Schlenk flask was filled with Ar, and sealed. The mixture was heated for 2 days at $160{ }^{\circ} \mathrm{C}$. After cooling to room temperature, water $(50 \mathrm{~mL})$ was added. The resulting precipitate was filtrated, washed with water, and methanol. The dried residue was subjected to column chromatography [silica, hot n-hexane/ $\mathrm{CHCl}_{3}(9 / 1)$ ] to afford after recrystallization in hexane a white powder $(673 \mathrm{mg}, 70 \%)$. m.p. $173.1^{\circ} \mathrm{C} ;{ }^{1} \mathrm{H} \mathrm{NMR}\left(300 \mathrm{MHz}, \mathrm{CDCl}_{3}\right) \delta=7.68(\mathrm{~d}, J=8.6$ $\mathrm{Hz}, 2 \mathrm{H}), 7.36(\mathrm{~d}, J=2.2 \mathrm{~Hz}, 2 \mathrm{H}), 7.03(\mathrm{dd}, J=8.7$ and $2.3 \mathrm{~Hz}, 2 \mathrm{H}), 4.04(\mathrm{t}, J=6.5 \mathrm{~Hz}, 4 \mathrm{H}), 1.92-1.73$ (m, $4 \mathrm{H}), 1.58-1.41(\mathrm{~m}, 4 \mathrm{H}), 1.40-1.12(\mathrm{~m}, 16 \mathrm{H}), 0.90(\mathrm{t}, J=6.8 \mathrm{~Hz}, 6 \mathrm{H}) ;{ }^{13} \mathrm{C} \mathrm{NMR}\left(75 \mathrm{MHz}, \mathrm{CDCl}_{3}\right) \delta=$ 157.2, 143.6, 131.2, 127.4, 121.8, 114.8, 108.0, 68.7, 32.0, 29.5, 29.4, 29.4, 26.2, 22.8, 14.2; HRMS (EI): $m / z$ calcd for $\mathrm{C}_{30} \mathrm{H}_{40} \mathrm{O}_{2} \mathrm{~S}_{2}: 496.2470$; found 496.2459 .

Synthesis of 2,7-bis((5-methylhexyl)oxy)-[1]benzothieno[3,2,b]benzothiophene (2b): A mixture of 2,7-diiodo-[1]benzothieno[3,2-b][1]benzothiophene (6) (492 mg, $1 \mathrm{mmol}$ ), CuI (76 mg, $0.4 \mathrm{mmol}$ ), 1,10phenanthroline (158 mg, $0.8 \mathrm{mmol})$, and $\mathrm{Cs}_{2} \mathrm{CO}_{3}(1.3 \mathrm{~g}, 4 \mathrm{mmol})$ in 5-methyl-1-hexanol $(7 \mathrm{~mL})$ in a Schlenk flask was degassed by 2 "freeze-pump-thaw" cycles. The Schlenk flask was filled with Ar, and sealed. The mixture was heated for 2 days at $160{ }^{\circ} \mathrm{C}$. After cooling to room temperature, water $(50 \mathrm{~mL})$ was added. The resulting precipitate was filtrated, washed with water, and methanol. The dried residue was subjected to column chromatography [silica, hot n-hexane/ $\mathrm{CHCl}_{3}$ (4/1)] to afford after recrystallization in hexane a white powder $(200 \mathrm{mg}, 43 \%)$. m.p. $172.7{ }^{\circ} \mathrm{C} ;{ }^{1} \mathrm{H} \mathrm{NMR}\left(300 \mathrm{MHz}, \mathrm{CDCl}_{3}\right) \delta$ $=7.67(\mathrm{~d}, J=8.7 \mathrm{~Hz}, 2 \mathrm{H}), 7.35(\mathrm{~d}, J=2.2 \mathrm{~Hz}, 2 \mathrm{H}), 7.02(\mathrm{dd}, J=8.7$ and $2.2 \mathrm{~Hz}, 2 \mathrm{H}), 4.03(\mathrm{t}, J=6.5 \mathrm{~Hz}, 4 \mathrm{H})$, 1.86-1.75 (m, 4H), 1.63-1.56 (m, 2H), 1.54-1.40 (m, 4H), 1.30-1.20 (m, 4H), 0.87 (d, J=6.6 Hz, 12H); ${ }^{13} \mathrm{C} \mathrm{NMR}\left(75 \mathrm{MHz}, \mathrm{CDCl}_{3}\right) \delta=157.0,143.4,131.0,127.2,121.6,114.6,107.8,68.6,38.7,29.5,27.9$, 23.9, 22.6; HRMS (MALDI): $\mathrm{m} / z$ calcd for $\mathrm{C}_{28} \mathrm{H}_{36} \mathrm{O}_{2} \mathrm{~S}_{2}: 468.2157$; found 468.2146.

Synthesis of 2,7-bis((7,7,8,8,8-pentafluorooctyl)oxy)-[1]benzothieno[3,2,b] benzothiophene (2c): A mixture of 2,7-diiodo-[1]benzothieno[3,2-b][1]benzothiophene (6) (492 mg, $1 \mathrm{mmol}$ ), CuI (76 mg, 0.4 
mmol), 1,10-phenanthroline (158 $\mathrm{mg}, 0.8 \mathrm{mmol})$, and $\mathrm{Cs}_{2} \mathrm{CO}_{3}(1.3 \mathrm{~g}, 4 \mathrm{mmol})$ in 7,7,8,8,8pentafluorooctanol $(4 \mathrm{~mL})$ in a Schlenk flask was degassed by 2 "freeze-pump-thaw" cycles. The Schlenk flask was filled with Ar, and sealed. The mixture was heated for 2 days at $160{ }^{\circ} \mathrm{C}$. After cooling to room temperature, water $(50 \mathrm{~mL})$ was added. The resulting precipitate was filtrated, washed with water, and methanol. The dried residue was subjected to column chromatography [silica, hot n-hexane/ $\mathrm{CHCl}_{3}(7 / 3)$ ] to afford after recrystallization in hexane a white powder $\left(323 \mathrm{mg}, 48 \%\right.$ ). m.p. $205.7{ }^{\circ} \mathrm{C} ;{ }^{1} \mathrm{H}$ NMR (400 $\left.\mathrm{MHz}, \mathrm{C}_{2} \mathrm{D}_{2} \mathrm{Cl}_{4}\right) \delta=7.75(\mathrm{~d}, J=8.7 \mathrm{~Hz}, 2 \mathrm{H}), 7.45(\mathrm{~d}, J=2.2 \mathrm{~Hz}, 2 \mathrm{H}), 7.11(\mathrm{dd}, J=8.7$ and $2.2 \mathrm{~Hz}, 2 \mathrm{H}), 4.13$ $(\mathrm{t}, J=6.4 \mathrm{~Hz}, 4 \mathrm{H}), 2.20-2.05(\mathrm{~m}, 4 \mathrm{H}), 1.96-1.87(\mathrm{~m}, 4 \mathrm{H}), 1.76-1.67(\mathrm{~m}, 4 \mathrm{H}), 1.66-1.52(\mathrm{~m}, 8 \mathrm{H}) ;{ }^{19} \mathrm{~F}$ NMR $\left(376 \mathrm{MHz}, \mathrm{C}_{2} \mathrm{D}_{2} \mathrm{Cl}_{4}\right) \delta=-84.8(\mathrm{~s}, 6 \mathrm{~F}),-116.77(\mathrm{t}, J=18.2 \mathrm{~Hz}, 4 \mathrm{~F}) ;{ }^{13} \mathrm{C} \mathrm{NMR}\left(100 \mathrm{MHz}, \mathrm{CDCl}_{3}\right) \delta=$ 157.0, 143.4, 131.1, 127.3, 121.5, 114.6, 108.6, 68.6, 30.6, 28.9, 28.6, 25.5, 20.2; HRMS (MALDI): $\mathrm{m} / \mathrm{z}$ calcd for $\mathrm{C}_{30} \mathrm{H}_{30} \mathrm{O}_{2} \mathrm{~F}_{10} \mathrm{~S}_{2}: 676.1528$; found 676.1520 .

Synthesis of 2,7-dioctylthio-[1]benzothieno[3,2,b]benzothiophene (3a): A mixture of 2,7-diiodo[1]benzothieno[3,2-b][1]benzothiophene (9) (982 mg, $2 \mathrm{mmol}$ ), CuI (152 mg, $0.8 \mathrm{mmol}$ ), 1,10phenanthroline $(317 \mathrm{mg}, 1.6 \mathrm{mmol})$, and $\mathrm{Cs}_{2} \mathrm{CO}_{3}(2.6 \mathrm{~g}, 8 \mathrm{mmol})$ in octanethiol $(40 \mathrm{~mL})$ in a Schlenk flask was degassed by 2 "freeze-pump-thaw" cycles. The Schlenk flask was filled with Ar, and sealed. The mixture was heated for 2 days at $160{ }^{\circ} \mathrm{C}$. After cooling to room temperature, water $(50 \mathrm{~mL})$ was added. The resulting precipitate was filtrated, washed with water, and methanol. The dried residue was subjected to column chromatography [silica, hot n-hexane/ $\left.\mathrm{CHCl}_{3}(7 / 3)\right]$ to afford after recrystallization in hexane a white powder $(693 \mathrm{mg}, 66 \%) .{ }^{1} \mathrm{H}$ NMR $\left(300 \mathrm{MHz}, \mathrm{CDCl}_{3}\right)$ m.p. $162.1{ }^{\circ} \mathrm{C} ; \delta=7.83(\mathrm{~d}, J=1.4$ $\mathrm{Hz}, 2 \mathrm{H}), 7.74(\mathrm{~d}, J=8.3 \mathrm{~Hz}, 2 \mathrm{H}), 7.41$ (dd, $J=8.3$ and $1.4 \mathrm{~Hz}, 2 \mathrm{H}), 3.00$ (broad s, 4H), 1.75-1.62 (m, 4H), $1.48-1.39(\mathrm{~m}, 4 \mathrm{H}), 1.36-1.20(\mathrm{~m}, 16 \mathrm{H}), 0.87(\mathrm{t}, J=6.7 \mathrm{~Hz}, 6 \mathrm{H}) ;{ }^{13} \mathrm{C} \mathrm{NMR}\left(75 \mathrm{MHz}, \mathrm{CDCl}_{3}\right) \delta=142.9$, 134.1, 132.8, 131.1, 126.6, 124.0, 121.4, 34.3, 31.8, 29.2, 29.1, 28.8, 22.6, 14.1; HRMS (MALDI): $\mathrm{m} / \mathrm{z}$ calcd for $\mathrm{C}_{30} \mathrm{H}_{40} \mathrm{~S}_{4}: 528.2013$; found 528.2015.

Synthesis of 2,7-Dithio-[1]benzothieno[3,2,b]benzothiophene (11): A suspension of 2,7-dibromo[1] benzothieno[3,2-b][1] benzothiophene (10) $(796 \mathrm{mg}, 2 \mathrm{mmol})$ in anhydrous DMA (60 mL) was treated with NaSMe $(2.27 \mathrm{~g}, 32 \mathrm{mmol})$, and the mixture was heated to $150{ }^{\circ} \mathrm{C}$ for $16 \mathrm{~h}$. After cooling to room temperature, $\mathrm{HCl} 2 \mathrm{M}(10 \mathrm{~mL})$ was added. The resulting precipitate was filtrated, washed with water, and methanol. The dried residue $(514 \mathrm{mg}, 84 \%)$ was used without further purification. ${ }^{1} \mathrm{H}$ NMR $(300 \mathrm{MHz}$, DMSO- $\left.d_{6}\right) \delta=8.06(\mathrm{~s}, 2 \mathrm{H}), 7.89(\mathrm{~d}, J=8.6 \mathrm{~Hz}, 2 \mathrm{H}), 7.43$ (d, $\left.J=8.6,2 \mathrm{H}\right), 5.75$ (s, 2H; HRMS (EI): $\mathrm{m} / z$ calcd for $\mathrm{C}_{14} \mathrm{H}_{8} \mathrm{~S}_{4}: 303.9509$; found 303.9516. A tendency towards rapid degradation has been observed and explains why no m.p. and ${ }^{13} \mathrm{C}$ NMR are reported.

Synthesis of 2,7-bis((5-methylhexyl)thio)-[1]benzothieno[3,2,b]benzothiophene (3b): A solution of 11 (305 mg, $1 \mathrm{mmol}$ ) in anhydrous DMF (40 mL) was treated with $\mathrm{K}_{2} \mathrm{CO}_{3}(345 \mathrm{mg}, 2.5 \mathrm{mmol})$. The mixture was stirred for $5 \mathrm{~min}$, and then 1-bromo-5-methylhexane (406 $\mu \mathrm{L}, 2.5 \mathrm{mmol})$ was added. The mixture was stiired for $16 \mathrm{~h}$ at $85{ }^{\circ} \mathrm{C}$. After cooling to room temperature, water $(80 \mathrm{~mL})$ was added. The resulting 
precipitate was filtrated, washed with water, and methanol. The filtered material was subjected to column chromatography [silica, hot n-hexane/ $\mathrm{CHCl}_{3}(7 / 3)$ ] to afford after recrystallization in hexane a white powder $(290 \mathrm{mg}, 58 \%)$. m.p. $163.5^{\circ} \mathrm{C} ;{ }^{1} \mathrm{H} \mathrm{NMR}\left(300 \mathrm{MHz}, \mathrm{CDCl}_{3}\right) \delta=7.85(\mathrm{~d}, J=1.6 \mathrm{~Hz}, 2 \mathrm{H}), 7.75(\mathrm{~d}$, $J=8.3 \mathrm{~Hz}, 2 \mathrm{H}), 7.42(\mathrm{dd}, J=8.3$ and $1.6 \mathrm{~Hz}, 2 \mathrm{H}), 3.00(\mathrm{t}, J=7.4 \mathrm{~Hz}, 4 \mathrm{H}), 1.73-1.59(\mathrm{~m}, 4 \mathrm{H}), 1.54-1.39$ (m, $6 \mathrm{H}), 1.24-1.14(\mathrm{~m}, 4 \mathrm{H}), 0.87(\mathrm{~d}, J=6.6 \mathrm{~Hz}, 12 \mathrm{H}) ;{ }^{13} \mathrm{C} \mathrm{NMR}\left(75 \mathrm{MHz}, \mathrm{CDCl}_{3}\right) \delta=143.0,134.1,132.9$, 131.1, 126.6, 124.0, 121.5, 38.4, 34.4, 29.4, 27.9, 26.6, 22.6; HRMS (EI): $m / z$ calcd for $\mathrm{C}_{28} \mathrm{H}_{36} \mathrm{~S}_{4}$ : 500.1700 ; found 500.1692 .

Purification: Samples 2a, 2c and 3a were purified by rapid sublimation on a cold finger at $290{ }^{\circ} \mathrm{C}$ under vacuum using a glass oven as a source of heat. The system was covered with aluminium foil to prevent samples from degradation via light exposure. Samples $\mathbf{2} \mathbf{b}$ and $\mathbf{3 b}$ were purified by recrystallisation from hexane.

Electrochemistry: Dichloromethane (HPLC grade) and tetra-n-butylammonium hexafluorophosphate (TBAP, electrochemical grade, Fluka was recrystallised from ethanol). Cyclic voltammetry (CV) was performed in a three-electrode cell equipped with a platinum millielectrode, a platinum wire counterelectrode and a silver wire used as a quasi-reference electrode. The electrochemical experiments were carried out under a dry and oxygen-free atmosphere $\left(\mathrm{H}_{2} \mathrm{O}<1 \mathrm{ppm}, \mathrm{O}_{2}<1 \mathrm{ppm}\right)$ in $\mathrm{CH}_{2} \mathrm{Cl}_{2}$ with TBAP $(0.1 \mathrm{M})$ as the support electrolyte. The voltammograms were recorded on a potentiostat/galvanostat (BioLogic - SP150) driven by the EC-Lab software with positive feedback compensation. Based on repetitive measurements, absolute errors on potentials were estimated to be $\approx \pm 5 \mathrm{mV}$. All the potential reported below, were calibrated versus Ferrocene/Ferrocenium oxidation potential $(+0.405 \mathrm{~V} v s \mathrm{SCE}$ or $+0.425 \mathrm{~V} v s \mathrm{Ag} / \mathrm{AgCl})$.

Photoelectron spectroscopy in air (PESA): The ionization potentials of powders, and drop-cast or spincoated films were measured with an AC-2 Photoelectron Spectrometer (RKI Instruments), working in ambient conditions. The films were deposited on gold layers supported on silicon substrates.

Crystal growth: Single crystals of compounds 1, 2a, 2b and $\mathbf{2 c}$ were grown by slow evaporation of unsaturated solutions of hexane, chloroform, 2-butanone and dichloromethane respectively (all HPLC grade). We were not able to obtain single crystals of compounds $\mathbf{3 a , b}$. Compound $\mathbf{3 b}$ proved to be unstable in ambient conditions, therefore crystallisation from dichloromethane led to the crystal formation of the corresponding oxidised form ( $\left.3 \mathbf{b}^{*}\right)$. Also the production of single crystals of the oxidised form for 3a proved to be difficult due to the presence of impurities appearing during the degradation process (see Figure S50).

Crystal structure: X-ray diffraction data for crystals of compounds $\mathbf{2 a}$, 2c were collected at $123 \mathrm{~K}$ with graphite monochromated $\mathrm{Cu} k \alpha$ radiation $(\lambda=1.5418 \AA)$ using an Oxford Diffraction Gemini $\mathrm{S}$ instrument. Data for $\mathbf{2 b}$ was collected at DIAMOND synchrotron radiation source by National Crystallographic Service, University of Southampton. All non-hydrogen atoms were refined 
anisotropically. Hydrogen atoms were included in calculated positions utilizing riding modes. All structures were refined to converge against F2 using the SHELXL-97 program. Detailed crystallographic data with refinement parameters are listed in complete crystallographic information files (CIF) and are available in the Supporting Information.

High Performance Liquid Chromatography (HPLC): An Agilent HP 1100 system equipped with a Supelco HPLC column $(150 \mathrm{~mm} \times 4.6 \mathrm{~mm} / 3 \mu \mathrm{m})$ and a UV detector was used to assess the purity of the analysed materials. Approximately $1 \mathrm{mg}$ of each sample was dissolved in $1 \mathrm{ml}$ of a mobile phase consisting of $70 \%$ hexane and $30 \%$ chloroform (both HPLC grade). The column temperature was set to $60{ }^{\circ} \mathrm{C}$ and the chromatograms were analysed at $254 \mathrm{~nm}$ (see Figures S46-51).

Nuclear Magnetic Resonance (NMR): The ${ }^{1} \mathrm{H}$ NMR spectra were recorded at 298 K on a Bruker Avance 300 spectrometer or at $363 \mathrm{~K}$ on a Varian VNMRS 400. Chemical shifts are reported in parts per million (ppm) with TMS as internal standard.

Mass spectrometry (MS): A Waters Autospec 6F or a Waters QToF Premier high-resolution mass spectrometers (HRMS) were used to obtain the mass spectra of the samples.

Thermogravimetry (TGA): Thermogravimetric analysis was performed on a Pyris 6 TGA instrument with Pyris software for instrument managing and data analysis. Approximately 3-5 mg of sample was scanned at a rate of $10{ }^{\circ} \mathrm{C} / \mathrm{min}$ from $30{ }^{\circ} \mathrm{C}$ to $500{ }^{\circ} \mathrm{C}$ for compounds $\mathbf{1}, \mathbf{2 a}-\mathbf{c}$, and $\mathbf{3 a}$, and $30{ }^{\circ} \mathrm{C}$ to $450{ }^{\circ} \mathrm{C}$ for compound $\mathbf{3 b}$, under a nitrogen purge at $20 \mathrm{~mL} / \mathrm{min}$ in open ceramic crucibles. The system was calibrated using alumel, nickel and perkalloy standards with reference temperatures of $154.2{ }^{\circ} \mathrm{C}, 355.3{ }^{\circ} \mathrm{C}$ and $596^{\circ} \mathrm{C}$ respectively.

Differential scanning calorimetry (DSC): Differential scanning calorimetry (DSC) analysis was performed on a Perkin Elmer Diamond DSC instrument with Pyris software for instrument managing and data analysis. Approximately 3-5 mg samples of compounds 1, 2a-c, and 3a,b were scanned at a rate of $10{ }^{\circ} \mathrm{C} / \mathrm{min}$ under a nitrogen purge at $20 \mathrm{~mL} / \mathrm{min}$ in aluminum pans with holes. Additionally, compound 3b was scanned at a rate of $1{ }^{\circ} \mathrm{C} / \mathrm{min}$ to obtain a better resolution. The system was calibrated using an indium and zinc standards with reference temperatures of $156.600{ }^{\circ} \mathrm{C}$ and $419.470{ }^{\circ} \mathrm{C}$ respectively.

Polarized optical microscopy (POM): A Nikon Eclipse 80i equipped with a heating stage and NISElements microscope imaging software was used to observe the texture of the liquid crystal phase of compounds $\mathbf{2 a}$.

Specular X-ray diffraction (sXRD): Specular X-ray diffraction (sXRD) measurements were performed on a Bruker D8 Advance diffractometer using $\mathrm{Cu} \mathrm{K \alpha}$ radiation $(\lambda=1.5418 \AA)$ equipped with a MRI (Material Research Instruments) heating stage for temperature-dependent measurements. Diffraction patterns were collected in the scattered angular range between $1.5^{\circ}$ and $30^{\circ}$ with an angular resolution of $0.02^{\circ}$ per step and a typical counting time of $10 \mathrm{~s}$ per step, using the $\theta / \theta$ reflection geometry. Powder patterns were also calculated using the atomic coordinates by programs within the Oscail package. 
Field effect transistors: Organic thin film transistors (OTFTs) were fabricated via spin-casting the organic semiconductor onto a heavily doped silicon wafer with a thermally grown, $200 \mathrm{~nm} \mathrm{SiO}_{2}$ layer as the gate dielectric. Molecule 1a was deposited from a 2 wt $\%$ chloroform solution, while molecules 2a and 3a were deposited from $1 \mathrm{wt} \%$ chloroform solutions. The films were then annealed at $120{ }^{\circ} \mathrm{C}$ for molecule 1a, $170{ }^{\circ} \mathrm{C}$ for molecule $2 \mathbf{a}$ and $150{ }^{\circ} \mathrm{C}$ for molecule 3a for 10 minutes. This was required to induce extended crystallisation of the small molecules. The devices were completed with Au source and drain electrodes evaporated through a shadow mask. Transistor channel widths were typically $1.5 \mathrm{~mm}$ and channel lengths were in the range $20-50 \mu \mathrm{m}$. Top gate devices were fabricated by spin coating molecule 3a onto silicon a substrate with ready-patterned Au electrodes (via the evaporation process explained above). To complete the structure an $800 \mathrm{~nm}$ layer of the Cytop gate dielectric $\left(C_{i}=2.1 \mathrm{nF} / \mathrm{cm}^{2}\right)$ was spin coated on top of the semiconductor followed by the evaporation of a patterned $\mathrm{Al}$ gate electrode using shadow mask in high vacuum $\left(10^{-6}\right.$ mbar). Electrical characteristics were measured with an Agilent B2902A semiconductor parameter analyser and device parameters were extracted from the equation $I_{D}=\mu W C_{i}\left(V_{G}-V_{T}\right)^{2} / 2 L$, where $I_{D}$ is the drain current, $\mu$ is the saturation mobility, $W$ is the channel width, $C_{i}$ is the geometric capacitance of the gate dielectric, $V_{G}$ is the gate voltage, $V_{T}$ is the threshold voltage and $L$ is the channel length. Device fabrication and electrical characterisation was performed entirely in nitrogen.

Quantum-chemical calculations and Kinetic Monte Carlo simulations: The ionization potentials of 1a and 2a were estimated as the energy difference between the neutral and positively charged molecules on the basis of their optimized geometries calculated with the semi-empirical Hartree-Fock MNDO method. ${ }^{78}$ The impact of solid-state effects on the ionization potential has been assessed with the help of a valence bond / Hartree-Fock MNDO model described in large details in literature. ${ }^{79,80}$ Briefly, the calculations are performed on small molecular clusters extracted from the crystal structures. The fragment orbital formalism allows assigning a different number of electrons on the different fragments so that it is possible to evaluate the electronic properties of charged molecules embedded in a condensed medium, including the induced polarization effects. Here, in practice, one molecule has been embedded in a cluster made of 27 and 37 molecules for $\mathbf{1 a}$ and 2a, respectively. The size of the cluster has been chosen such that there are at least two layers of molecules within the crystalline plane and one layer of molecules in the interlayer direction. The IP has then been estimated by subtracting the energy of the neutral cluster to the energy of the cluster with the central molecule positively charged. We neglect here a possible delocalization of the charge over the neighboring molecules since our primary goal is to demonstrate that packing effects can lead to significant changes in the solid-state polarization effects rather than to assess the exact delocalization of the charge in the crystal. 
The hole transport properties of $\mathbf{1 a}$ and 2a have been described using the Marcus-Levich-Jortner formalism. This model assumes that charges are hopping between neighboring molecules and expresses the rate of hole transfer $\mathrm{k}_{\mathrm{hop}}$ as: ${ }^{81}$

$k_{\text {hop }}=\frac{4 \pi^{2}}{h} J^{2} \frac{1}{\sqrt{4 \pi \lambda_{S} k_{B} T}} \sum_{v} \exp (-S) \frac{S^{v}}{v !} \exp \left[-\frac{\left(\lambda_{S}+v \hbar \omega+\Delta G^{0}\right)^{2}}{4 \lambda_{S} k_{B} T}\right]$

where $S$ is the Huang-Rhys factor which is related to the internal reorganization energy $\lambda_{\mathrm{i}}\left(\mathrm{S}=\lambda_{\mathrm{i}} / \hbar \omega\right), \mathrm{J}$ the transfer integral, $\lambda_{\mathrm{s}}$ the external reorganization energy, $\mathrm{k}_{\mathrm{B}}$ the Boltzmann constant, $\mathrm{T}$ the temperature, $\Delta \mathrm{G}^{\circ}$ the free energy of the reaction and $\hbar \omega$ an effective vibrational mode (carbon-carbon stretching mode) assisting charge transport. The internal reorganization energy entering the Huang-Rhys factor is a parameter that reflects the geometric changes of the molecules involved in the charge transfer process It has been evaluated at the DFT level (B3LYP/6-31g**) according to the procedure described elsewhere. ${ }^{73}$ The $\hbar \omega$ effective stretching mode was set to $0.2 \mathrm{eV}$ and the external reorganization energy to a typical value of $0.1 \mathrm{eV} .{ }^{82}$ The HOMO transfer integral $(\mathrm{J})$ describes the amplitude of the interactions between the HOMO electronic levels of the two molecules involved in the hole transfer process. This term has been estimated in a fragment approach at the DFT level (B3LYP/DZ) with the Amsterdam Density Functional (ADF) package ${ }^{83}$ as described elsewhere. ${ }^{42,84}$ Due to the weak energetic disorder in crystals, $\Delta \mathrm{G}^{\circ}$ can be expressed solely as $\Delta \mathrm{G}^{\circ}=\mathrm{e} \overrightarrow{\mathrm{F}} \overrightarrow{\mathrm{d}}$, where $\overrightarrow{\mathrm{F}}$ and $\overrightarrow{\mathrm{d}}$ are the electric field vector and the distance vector between mass centers, respectively. Finally, the charge carrier mobility $(\mu)$ was evaluated using a Kinetic Monte Carlo technique with the First Reaction Method algorithm. This technique allows us to propagate a single charge carrier in the crystals following a stochastic dynamics where the direction taken by the charge in the crystal in each Monte Carlo cycle is chosen according to the smallest hopping time. The hopping time $t_{i j}$ between two molecules $i$ and $j$ is related to the hopping rate $k_{i j}$ with the following expression:

$t_{i j}=-\frac{\ln (r)}{k_{i j}}$

where $r$ is a random number chosen between 0 and 1 . The charge carrier mobility is obtained at the end of the simulation as:

$\mu=\frac{d_{t o t}}{t_{t o t} F}$

where $d_{t o t}$ and $t_{t o t}$ are the total distance travelled during the Kinetic Monte Carlo simulation and the total time of the simulation obtained as the sum of the $t_{i j}$ values, respectively. 


\section{ACKNOWLEDGEMENTS}

This work has been financially supported by a concerted research action of the French Community of Belgian (ARC project $\mathrm{N}^{\circ} 20061$ ), by the Walloon Region (WCS project $\mathrm{N}^{\circ} 1117306$ ), by the European Commission / Walloon Region (FEDER - Smartfilm RF project), by the Interuniversity Attraction Pole program of the Belgian Federal Science Policy Office (PAI 7/05), the Programme d'Excellence de la Région Wallonne (OPTI2MAT project), by the Belgian National Fund for Scientific Research (FNRS, POLYGRAD project $\mathrm{N}^{\circ} 22333186$ ), by the ERC project SUPRAFUNCTION (GA-257305), by the EC Marie-Curie projects IEF-MULTITUDES (PIEF-GA-2012-326666) and ITN iSwitch (GA no. 642196), by the Agence Nationale de la Recherche through the LabEx project Chemistry of Complex Systems (ANR-10- LABX-0026_CSC), and by the International Center for Frontier Research in Chemistry (icFRC). Y. G. has benefited from a mandate of Francqui Research Professor (2011-2015). J.C. is a FNRS Research Director. B.C. is a FNRS Research Fellow. G. S. acknowledges postdoctoral fellowship support from the Wiener-Anspach Foundation. Thanks are due to the National Crystallography Service, University of Southampton, for data collection on structure $\mathbf{2 b}$. OF is a Royal Society University Research Fellow. 


\section{REFERENCES}

[1] Organic Electronics: Materials, Manufacturing, and Applications, (Ed.: H. Klauk), Wiley-VCH, Weinheim, 2006.

[2] Organic Field-Effect Transistors (Eds.: Z. Bao, J. Locklin), CRC Press, Boca Raton, 2007.

[3] Organic Electronics II (Ed.: H. Klauk), Wiley-VCH, Weinheim, 2012.

[4] J.-M. Cho, T. Higashino, T. Mori, Appl. Phys. Lett. 2015, 106, 193303.

[5] D. He, Y. Zhang, Q. Wu, R. Xu, H. Nan, J. Liu, J. Yao, Z. Wang, S. Yuan, Y. Li, Y. Shi, J. Wang, Z. Ni, L. He, F. Miao, F. Song, H. Xu, K. Watanabe, T. Taniguchi, J.-B. Xu, X. Wang, Nat. Commun. 2014, 5,5162 .

[6] Y. Krupskaya, M. Gibertini, N. Marzari, and A.F. Morpurgo, Adv. Mater. 2015, 27, 2453-2458.

[7] H. Lino, T. Usui, J.-I. Hanna, Nature Commun. 2015, 6, 6828.

[8] C. Mitsui, T. Okamoto, M. Yamagashi, J. Tsurumi, K. Yoshimoto, K. Kakahara, J. Soeda, Y. Hirose, H. Sato, A. Yamano, T. Uemura, J. Takeya, Adv. Mater. 2014, 26, 4546-4551.

[9] Jeong-Il Park, J.W. Chung, J.-Y. Kim, J. Lee, J. Y. Jung, B. Koo, B.-L. Lee, S. W. Lee, Y. W. Jin, S. Y. Lee, J. Am. Chem. Soc. 2015, 137, 12175-12178.

[10] G. Schweicher, Y. Olivier, V. Lemaur and Y. H. Geerts, Isr. J. Chem., 2014, 54, 595-620.

[11] G. Schweicher, V. Lemaur, C. Niebel, C. Ruzié, Y. Diao, O. Goto, W.-Y. Lee, Y. Kim, J.-B. Arlin, J. Karpinska, A. R. Kennedy, S. R. Parkin, Y. Olivier, S. C. B. Mannsfeld, J. Cornil,Y. H. Geerts, Z. Bao, Adv. Mater. 2015, 27, 3066-3072.

[12] A. N. Sokolov, S. Atahan-Evrenk, R. Mondal, H. B. Akkerman, R. S. Sânchez-Carrera, S. GranadosFocil, J. Schrier, S. C. B. Mannsfeld, Arjan P. Zoombelt, Z. Bao, A. Aspuru-Guzik, Nat. Commun. 2011, 2, 437-445.

[13] B. Blülle, R. Häusermann, B. Batlogg, Phys. Rev. Appl. 2014, 1, 034006.

[14] P.S. Jo, D.T. Duong, J. Park, R. Sinclair, A. Salleo, Chem. Mater. 2015, 27, 3979-3987.

[15] M.A. Reyes-Martinez, A.J. Crosby, A. Briseno, Nat. Commun. 2015, 6, 6948.

[16] H.T. Yi, Y. Chen, K. Czelen, V. Podzorov, Adv. Mater. 2011, 23, 5807-5811.

[17] M. Watanabe, K.-Y. Chen, Y.Y. Chang, T.J. Chow, Acc. Chem. Res. 2013, 46, 1606-1615.

[18] J. E. Anthony, Chem. Rev. 2006, 106, 5028 -5048.

[19] J. E. Anthony, Angew. Chem. Int. Ed. 2008, 47, 452-483.

[20] Y. Mei, M.A. Loth, M. Payne, W. Zhang, J. Smith, C.S. Day, S.R. Parkin, M. Heeney, I. McCulloch, T.D. Anthopoulos, J.E. Anthony, O.D. Jurchescu, Adv. Mater. 2013, 25, 4352-4357.

[21] C. Liu, T. Minari, X. Lu, A. A. Kumatani, K. Takimiya, K. Tsukagoshi, Adv. Mater. 2011, 23, $523-$ 526.

[22] H. Minemawari, T. Yamada, H. Matsui, J. Tsutsumi, S. Haas, R. Chiba, R. Kumai, T. Hasegawa, Nature 2011, 475, 364-367. 
[23] C. Niebel, Y. Kim, C. Ruzié, J. Karpinska, B. Chattopadhyay, G. Schweicher, A. Richard, V.

Lemaur, Y. Olivier, J. Cornil, A. R. Kennedy, Y. Diao, W.-Y. Lee, S. Mannsfeld, Z. Bao, Y. H. Geerts, J. Mater. Chem. C, 2015, 3, 674-685.

[24] K. Niimi, S. Shinamura, I. Osaka, E. Miyazaki, K. Takimiya, J. Am. Chem. Soc. 2011, 133, 87328739.

[25] M. Abe, T. Mori, I. Osaka, K. Sugimoto, K. Takimiya, Chem. Mater., 2015, 27, 5049-5057.

[26] T. Okamoto, C. Mitsui, M. Yamagishi, K. Nakahara, J. Soeda, Y. Hirose, K. Miwa, H. Sato, A. Yamano, T. Matsushita, T. Uemura, J. Takeya, Adv. Mater. 2013, 25, 6392-6397.

[27] Y. Yuan, G. Giri, A. L. Ayzner, A. P. Zoombelt, S. C. B. Mannsfeld, J. Chen, D. Nordlund, M. F. Toney, J. Huang, Z. Bao, Nat. Commun. 2013, 4, 3005.

[28] J. Skabara, J.-B. Arlin, Y. H. Geerts, Adv. Mater. 2013, 25, 1948-1954.

[29] Y. Chen, B. Lee, H. T. Yi, S. S. Lee, M. M. Payne, S. Pola, C.-H. Kuo, Y.-L. Loo, J. E. Anthony, Y. T. Tao, V. Podzorov, Phys. Chem. Chem. Phys. 2012, 14, 14142-14151.

[30] H. Yada, R. Uchida, H. Sekine, T. Terashige, S. Tao, H. Matsui, N. Kida, S. Fratini, S. Ciuchi, Y. Okada, T. Uemura, J. Takeya, H. Okamoto, Appl. Phys. Lett. 2014, 105, 143302

[31] S. Seki, A. Saeki, T. Sakurai and D. Sakamaki, Phys. Chem. Chem. Phys. 2014, 16, 11093-11113.

[32] H. Tanaka, M. Kozuka, S.-i. Watanabe, H. Ito, Y. Shimoi, K. Takimiya, S.-i. Kuroda, Phys. Rev. B. 2011, 84, 081306(R).

[33] H. Tanaka, M. Hirate, S.-i. Watanabe, K. Kaneko, K. Marumoto, T. Takenobu, Y. Isawa, S.-i. Kuroda, Phys. Rev. B. 2013, 87, 045309.

[34] Y. Kinoshita, H. Tanaka, Y. Shimoi, K. Takimiya, S.-i. Kuroda, Appl. Phys. Lett. 2014, 105, 033301.

[35] V. Podzorov, E. Menard, J. A. Rogers, M. E. Gershenson, Phys. Rev. Lett. 2005, 95, 226601.

[36] Y. Okada, K. Sakai, T. Uemura, Y. Nakazawa, J. Takeya, Phys. Rev. B 2011, 84, 245308.

[37] G. Heimel, L. Romaner, E. Zojer, J. L. Brédas, Acc. Chem. Res. 2008, 41, 721-729.

[38] M. Marinkovic, D. Belaineh, V. Wagner, D. Knipp, Adv. Mater. 2012, 24, 4005-4009.

[39] C. M. Cardona, W. Li, A. E. Kaifer, D. Stockdale, G. C. Bazan, Adv. Mater., 2011, 23, 2367-2371.

[40] S. M. Ryno, S. R. Lee, J. S. Sears, C. Risko, J.-L. Brédas, J. Phys. Chem. C 2013, 117, 1385313860.

[41] S. M. Ryno, C. Risko, J.-L. Brédas, J. Am. Chem. Soc. 2014, 136, 6421-6427.

[42] E.F. Valeev, V. Coropceanu, D.A. da Silva Filho, S. Salman, J.-L. Brédas, J. Am. Chem. Soc. 2006, 128, 9882-9886.

[43] O. Lobanova Griffith, J. E. Anthony, A. G. Jones, D. L. Lichtenberger, J. Am. Chem. Soc. 2010, 132, $580-586$.

[44] O. Lobanova Griffith, A. G. Jones, J. E. Anthony, D. L. Lichtenberger, J. Phys. Chem. C 2010, 114, $13838-13845$. 
[45] N. Koch, I. Salzmann, R.L. Johnson, J. Pfaum, R. Friedlein, J.P. Rabe, Org. Electr. 2006, 7, 537545.

[46] O. D. Jurchescu, J. Baas, T. T. M. Palstra, Appl. Phys. Lett. 2004, 84, 3061-3063.

[47] A. Voloshenko, K. J. Tan, C. Kloc, O. Lev. M. Shelkov, S. Sladkevich, P. V. Prikhodchenko, J. Gun, Org. Electron. 2013, 14, 378-388.

[48] Y. Chen, S. Subramanian, S.R. Parkin, M. Siegler, K. Gallup, C. Haughn, D.C. Martin, J.E. Anthony, J. Mater. Chem. 2008, 18, 1961-1969.

[49] K. Takimiya, I. Osaka, T. Mori and M. Nakano, Acc. Chem. Res., 2014, 47, 1493-1502.

[50] I. Yavuz, B.N. Martin, J. Park, K.N. Houk, J. Am. Chem. Soc. 2015, 137, 2856-2866.

[51] J. Rivnay, S.C.B. Mannsfeld, C.E. Miller, A. Salleo, M.F. Toney, Chem. Rev. 2012, 112, 5488-5519.

[52] A. O. F. Jones, Y. H. Geerts, J. Karpinska, A. R. Kennedy, R. Resel, C. Röthel, C. Ruzié, O. Werzer, M. Sferrazza, ACS Appl. Mater. Interfaces 2015, 7, 1868-1873.

[53] The synthesis of the BTBT derivative 2a has previously been described as supporting information of a paper devoted to physical aspects, see [52].

[54] The bulk crystal structure of 2a has briefly been introduced in [52], as part of a study of substrateinduced polymorphism. Here, it is fully analyzed, discussed, and compared with crystal structure of $\mathbf{1}$, $2 b, c$ and $3 b^{*}$.

[55] X. Y. Cheng, Y. Y. Noh, J. P. Wang, M. Tello, J. Frisch, R. P. Blum, A. Vollmer, J. P. Rabe, N. Koch, H. Sirringhaus, Adv. Funct. Mater. 2009, 19, 2407-2415.

[56] S. Sergeyev, W. Pisula, Y. H. Geerts, Chem. Soc. Rev. 2007, 36, 1902-1929.

[57] M. Wolter, G. Nordmann, G. E. Job, S. L. Buchwald, Org. Lett. 2002, 4, 973-976.

[58] K. Takimiya, H. Ebata, K. Sakamoto, T. Izawa, T. Otsubo, Y. Kunugi, J. Am. Chem. Soc. 2006, 128, 12604-12605.

[59] S. Y. Zherdeva, A. Barudi, A. Y. Zheltov, B. I. Stepanov, J. Org. Chem. USSR 1980, 16, 383-390.

[60] T. A. Wark, D. W. Stephan, Organometallics 1989, 8, 2836-2843.

[61] S. Heuser, D. G. Barrett, M. Berg, B. Bonnier, A. Kahl, M. L. De La Puente, N. Oram, R. Riedl, U. Roettig, G. S. Gil, E. Seger, D. J. Steggles, J. Wanner, A. G. Weichert, Tetrahedron Lett. 2006, 47, $2675-$ 2678.

[62] J. Y. Hwang, L. A. Arnold, F. Zhu, A. Kosinski, T. J. Mangano, V. Setola, B. L. Roth, R. K. Guy, J. Med. Chem. 2009, 52, 3892-3901.

[63] H. Ebata, T. Izawa, E. Miyazaki, K. Takimiya, M. Ikeda, H. Kuwabara, T. Yui, T., J. Am. Chem. Soc. 2007, 129, 15732-15733.

[64] H. H. Jaffé, Chem. Rev. 1953, 53, 191-261.

[65] D. T. Glatzhofer, M. C. Morvant, J. Phys. Org. Chem. 1998, 11, 731-736.

[66] H. C. Brown, Y. Okamoto, J. Am. Chem. Soc. 1958, 80, 4979-4987. 
[67] J. M. Pernaut, P. Audebert, P. Hapiot, P. Garcia, J. Braz. Chem. Soc. 1994, 5, 127-130.

[68] T. Izawa, E. Miyazaki, K. Takimiya, Adv. Mater. 2008, 20, 3388-3392.

[69] K. Takimiya, S. Shinamua, I. Osaka, E. Miyazaki, Adv. Mater. 2011, 23, 4347-4370.

[70] M. A. Spackman, D. Jayatilaka, CrystEngComm 2009, 11, 19-32.

[71] H. Kobayashi, N. Kobayashi, S. Hosoi, N. Koshitani, D. Murakami, R. Shirasawa, Y. Kudo, D. Hobara, Y. Tokita, M. Itabashi, J. Chem. Phys. 2013, 139, 014707.

[72] J.D. Huang, S. Chai, H. Ma, B. Dong, J. Phys. Chem. C 2015, 119, 33.

[73] V. Lemaur, D. da Silva Filho, V. Coropceanu, M. Lehmann, Y. Geerts, J. Piris, M. Debije, A. van de Craats, K. Senthilkumar, L. Siebbeles, J. Am. Chem. Soc. 2004, 126, 3271-3279.

[74] J. Tant, Y.H. Geerts, M. Lehmann, V. De Cupere, G. Zucchi, B.W. Laursen, T. Bjornholm, V. Lemaur, V. Marcq, A. Burquel, E. Hennebicq, F. Gardebien, P. Viville, D. Beljonne, R. Lazzaroni, J. Cornil, J. Phys. Chem. B 2005, 109, 20315-20323.

[75] B. Košata, V. Kozmik, J.Svoboda, V. Novotnà, P. Vaněk, M.Glogarovà, Liq. Cryst. 2003, 30, 603610.

[76] M. Saito, I. Osaka, E. Miyazaki, K. Takimiya, H. Kuwabara, M. Ikeda, Tetrahedron Lett. 2011, 52, 285-288.

[77] Košata, B.; Kozmík, V.; Svoboda, J. Collect. Czech. Chem. Commun. 2002, 67, 645-664.

[78] M.J.S. Dewar, W. Thiel, J. Am. Chem. Soc. 1977, 99, 4899-4907.

[79] F. Castet, A. Fritsch, L. Ducasse, J .Phys. I, 1996, 6, 583-598.

[80] F. Castet, P. Aurel, A. Fritsch, L. Ducasse, D. Liotard, M. Linares, J. Cornil, D. Beljonne, Phys. Rev. B 2008, 77, 115210 .

[81] V. Coropceanu, J. Cornil, D. da Silva Filho, Y. Olivier, R. Silbey, J.L. Brédas, Chem. Rev. 2007, 107, 926-952.

[82] N.G. Martinelli, J. Idé, R. S. Sánchez-Carrera, V. Coropceanu, J.-L. Brédas, L. Ducasse, F. Castet, J. Cornil, D. Beljonne, J. Phys. Chem. C, 2010, 114, 20678-20685.

[83] G. Te Velde, F.M. Bickelhaupt, E.J. Baerends, C. Fonseca Guerra, S.J. van Gisbergen, J.G. Snijders, T. Ziegler, J. Comput. Chem. 2001, 22, 931-967.

[84] L. Viani, Y. Olivier, S. Athanasopoulos, D.A. da Silva Filho, J. Hulliger, J.-L. Brédas, J. Gierschner, J. Cornil, ChemPhysChem 2010, 11, 1062-1068.

[85] C. Hansch, A. Leo, R.W. Taft, Chem. Rev. 1991, 91, 165-195. 


\section{FIGURES, SCHEMES, \& TABLES}<smiles>[R]c1ccc2c(c1)sc1c3ccc([R])cc3sc21</smiles>

$1 a$<smiles>[R]Oc1ccc2c(c1)sc1c3ccc([R])cc3sc21</smiles>

2a-c<smiles>[R5]c1ccc2c(c1)sc1c3ccc([R5])cc3sc21</smiles>

$3 a, b$<smiles>[123I]Cc1ccc2c(c1)sc1c3ccccc3sc21</smiles><smiles>O=[N+]([O-])c1ccc2c(c1)sc1c3ccc([N+](=O)[O-])cc3sc21</smiles>

$\mathrm{Ph}$<smiles>Ic1ccc2c(c1)sc1c3ccc(-c4ccccc4)cc3sc21</smiles><smiles>Nc1ccc2c(c1)sc1c3ccccc3sc21</smiles>

7<smiles>c1ccc2c(c1)sc1c3ccccc3sc21</smiles>

8<smiles>CCCCCCCCC</smiles>

Figure 1. Molecular structures of the BTBT derivatives considered in this study.

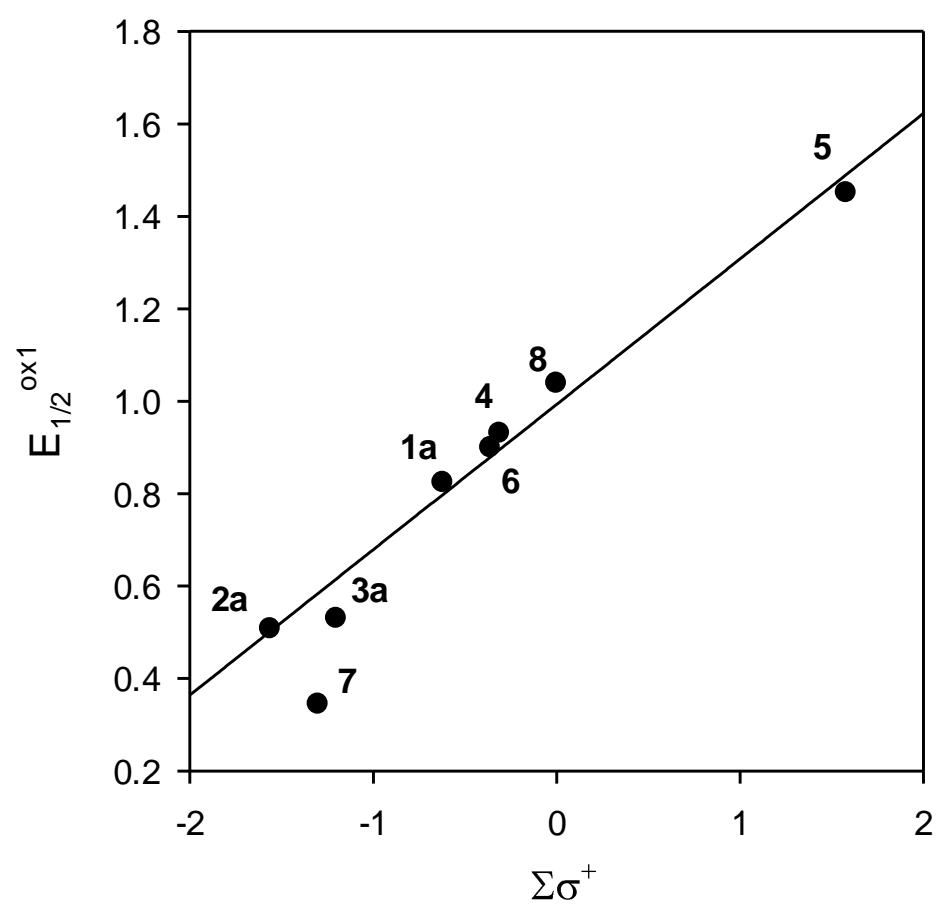

Figure 2. Hammett plot of the variation of the first oxidation potential among substituted and unsubstituted BTBT as function of the Brown coefficient of their substituents. 

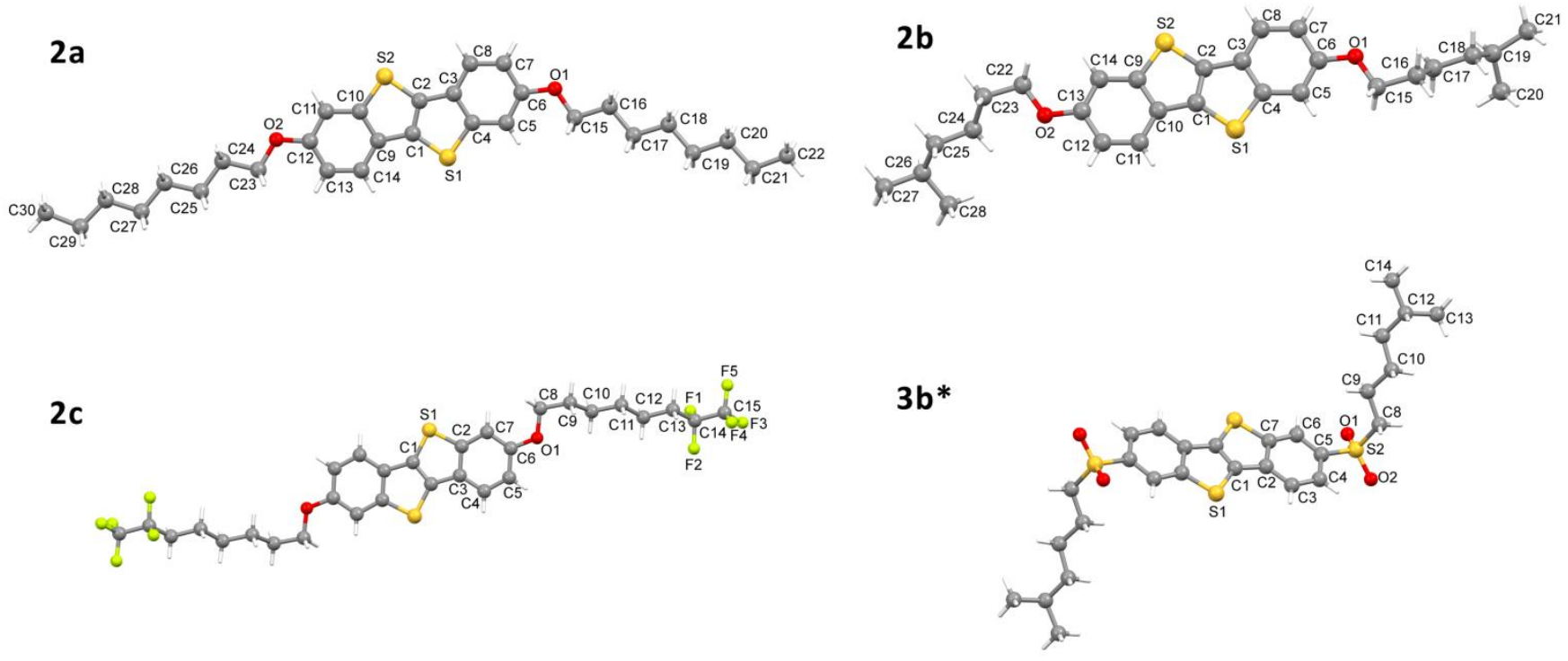

Figure 3. Molecular view of compounds $\mathbf{2} \mathbf{a}-\mathbf{c}$ and $\mathbf{3} \mathbf{b}^{*}$ with the atom labelling scheme. For $\mathbf{2} \mathbf{c}$ and $\mathbf{3} \mathbf{b}^{*}$, the atoms generated by symmetry are not labelled.
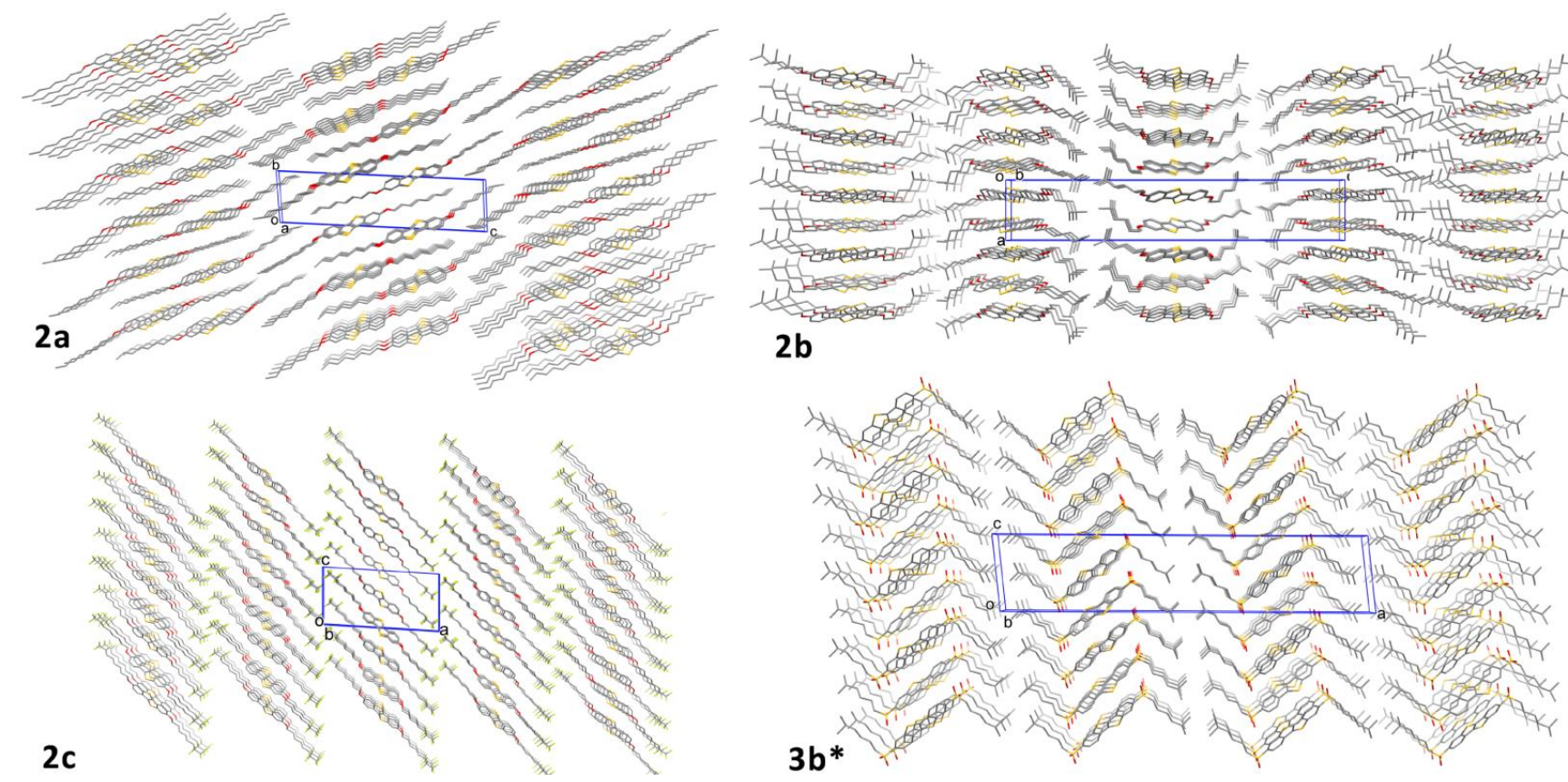

2b

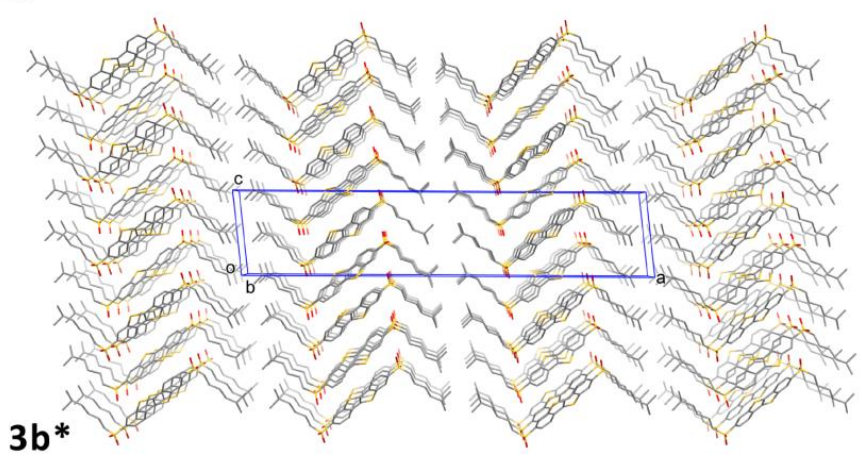

Figure 4. A perspective view of the crystal packing of $\mathbf{2} \mathbf{a}-\mathbf{c}$ and $\mathbf{3} \mathbf{b}^{*}$ showing the alkyl chain behavior 

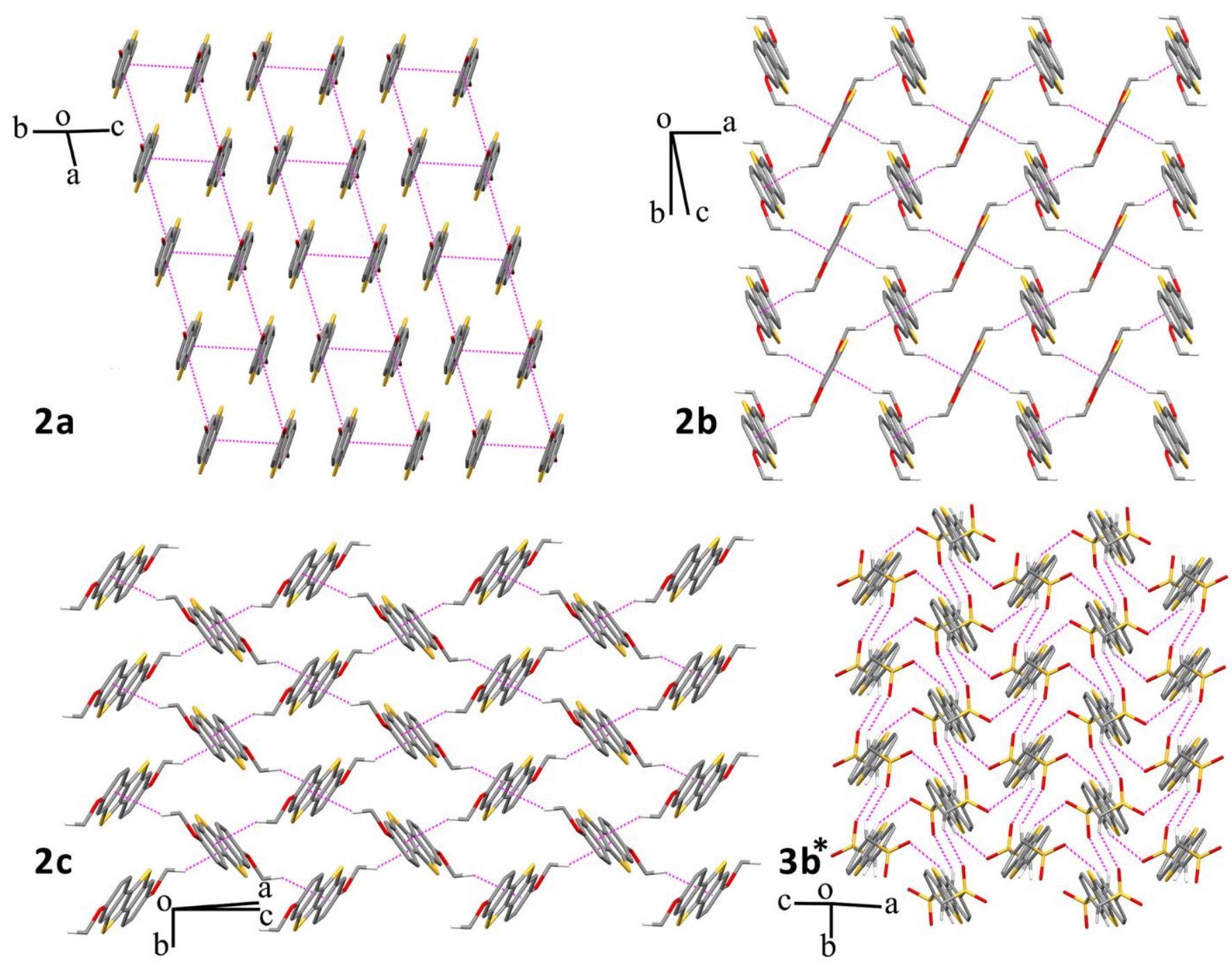

Figure 5. Crystal packing of the aromatic cores in $\mathbf{2 a - c}$ and $\mathbf{3} \mathbf{b}^{*}$ showing the formation of a $\pi$-stacked ladder architecture in $\mathbf{2 a}$, and herringbone like motif in $\mathbf{2 b}$, $\mathbf{c}$ and $\mathbf{3} \mathbf{b}^{*}$. Only the BTBT-cores and atoms driving the packing are shown for clarity. 

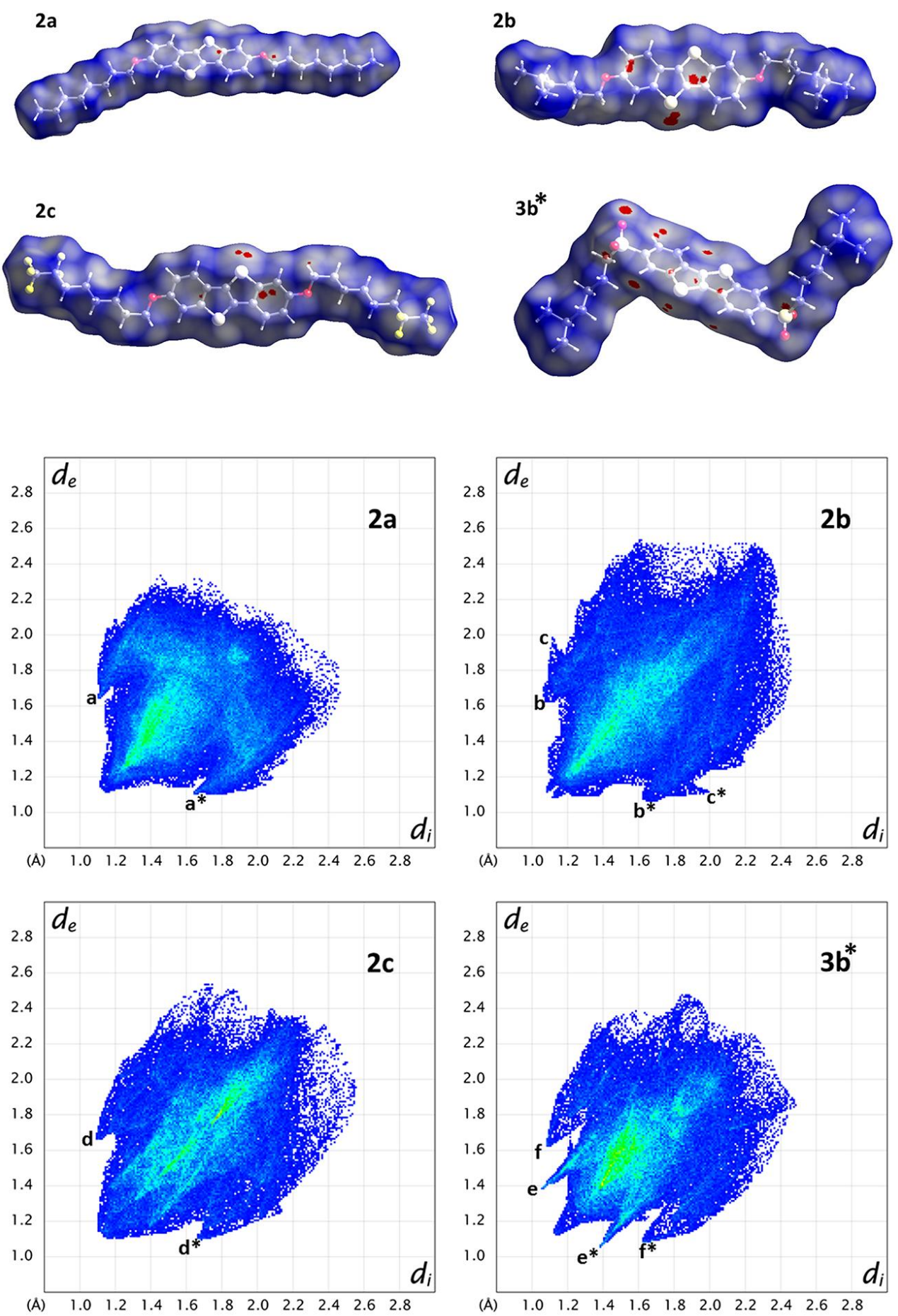

Figure 6. Hirshfeld surfaces and the corresponding fingerprint plots for compounds $\mathbf{2 a - c}$, and $\mathbf{3 b}$. 


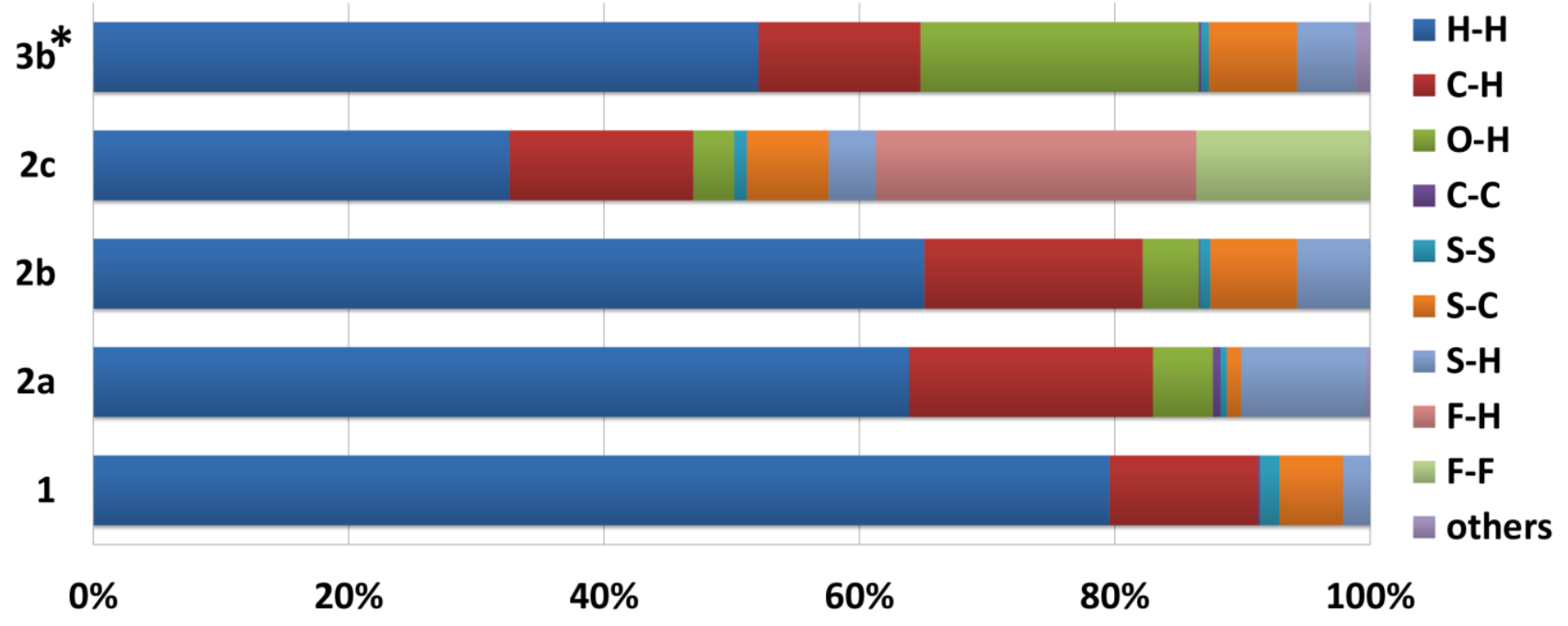

Figure 7. Relative contributions (in \%) to the Hirshfeld surface areas for the various intermolecular contacts in 1, 2a-c and 3b* 

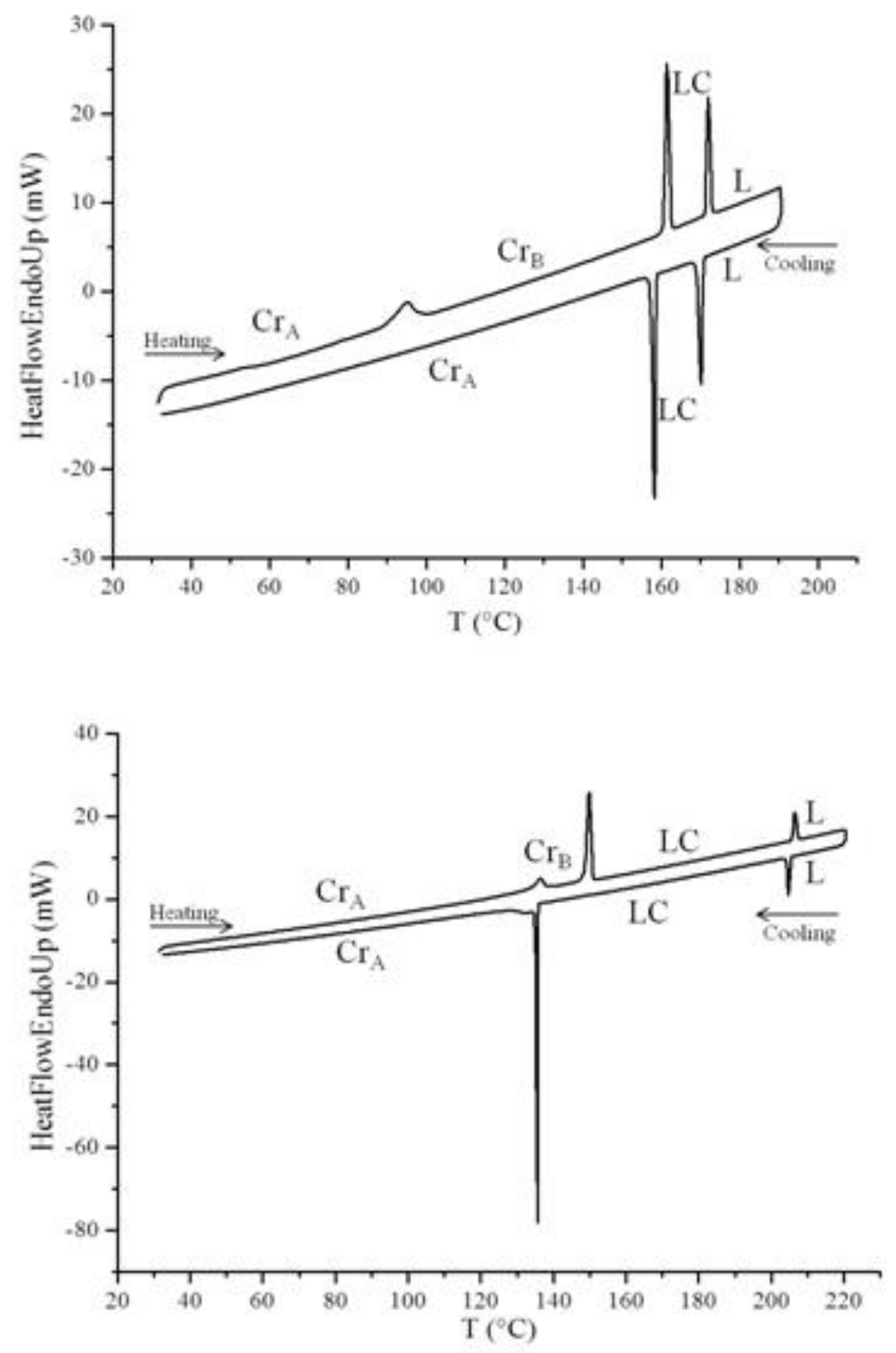

Figure 8. DSC traces of compounds 2a (top) and 2c (bottom) exhibiting crystalline and liquid crystalline phases (second heating and cooling scans at $10{ }^{\circ} \mathrm{C} / \mathrm{min}$ ). 

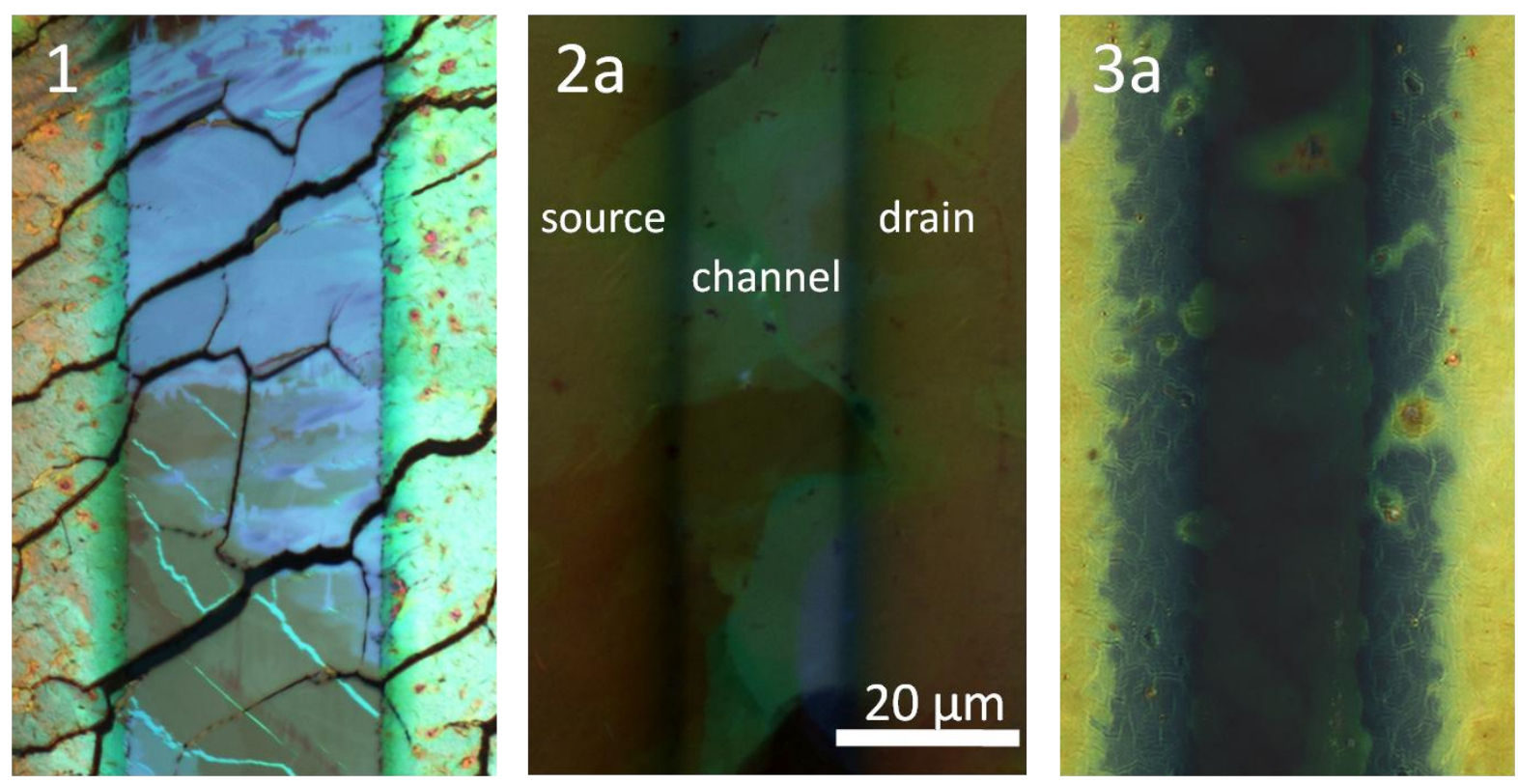

Figure 9. Polarized optical micrographs of the transistors fabricated using the semiconducting molecules 1a, 2a, and 3a.
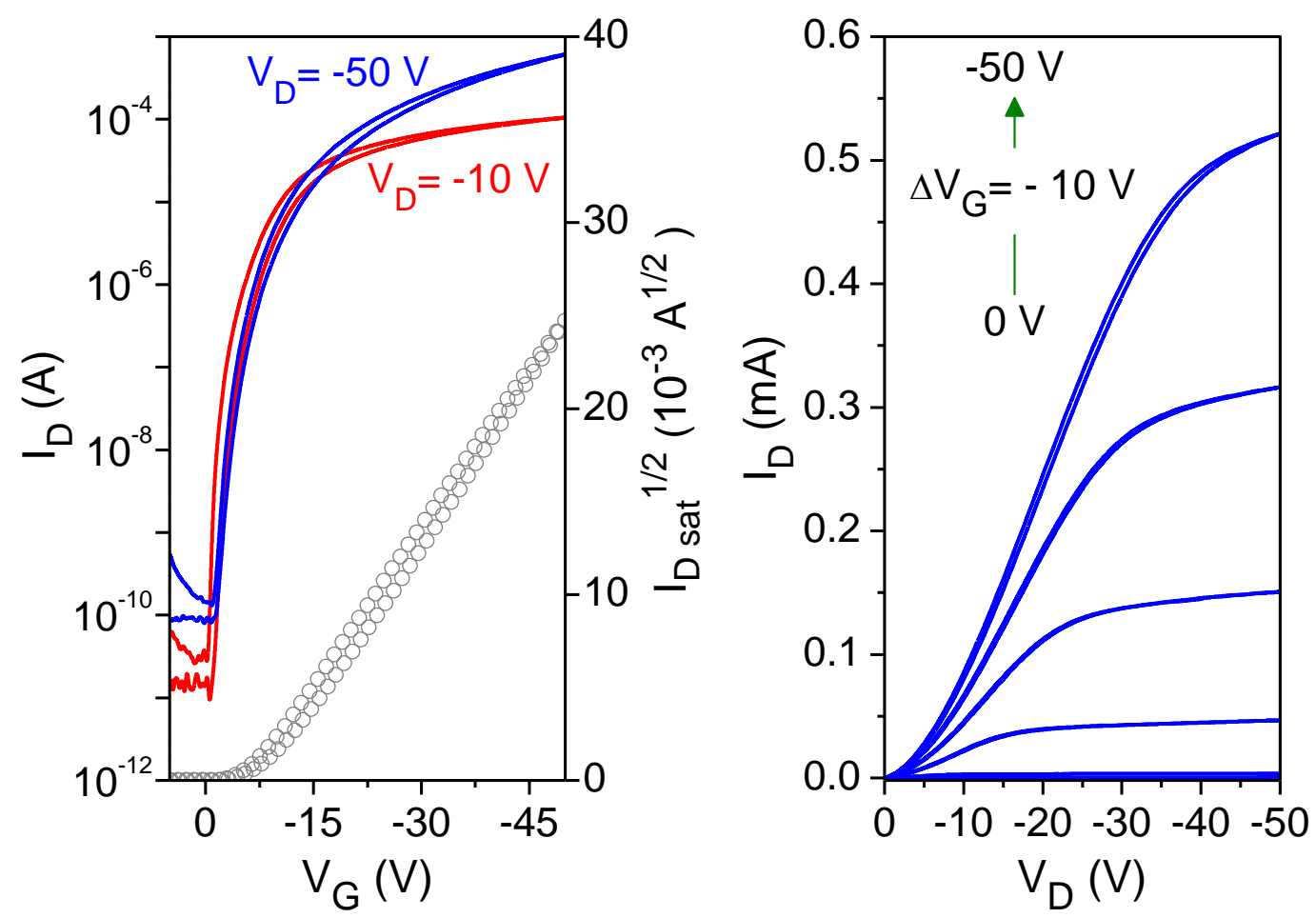

Figure 10. Transfer and output characteristics of a bottom-gate OTFT fabricated with molecules 1a. The transistor channel dimensions were $\mathrm{L}=50 \mu \mathrm{m}$ and $\mathrm{W}=1.5 \mathrm{~mm}$. 

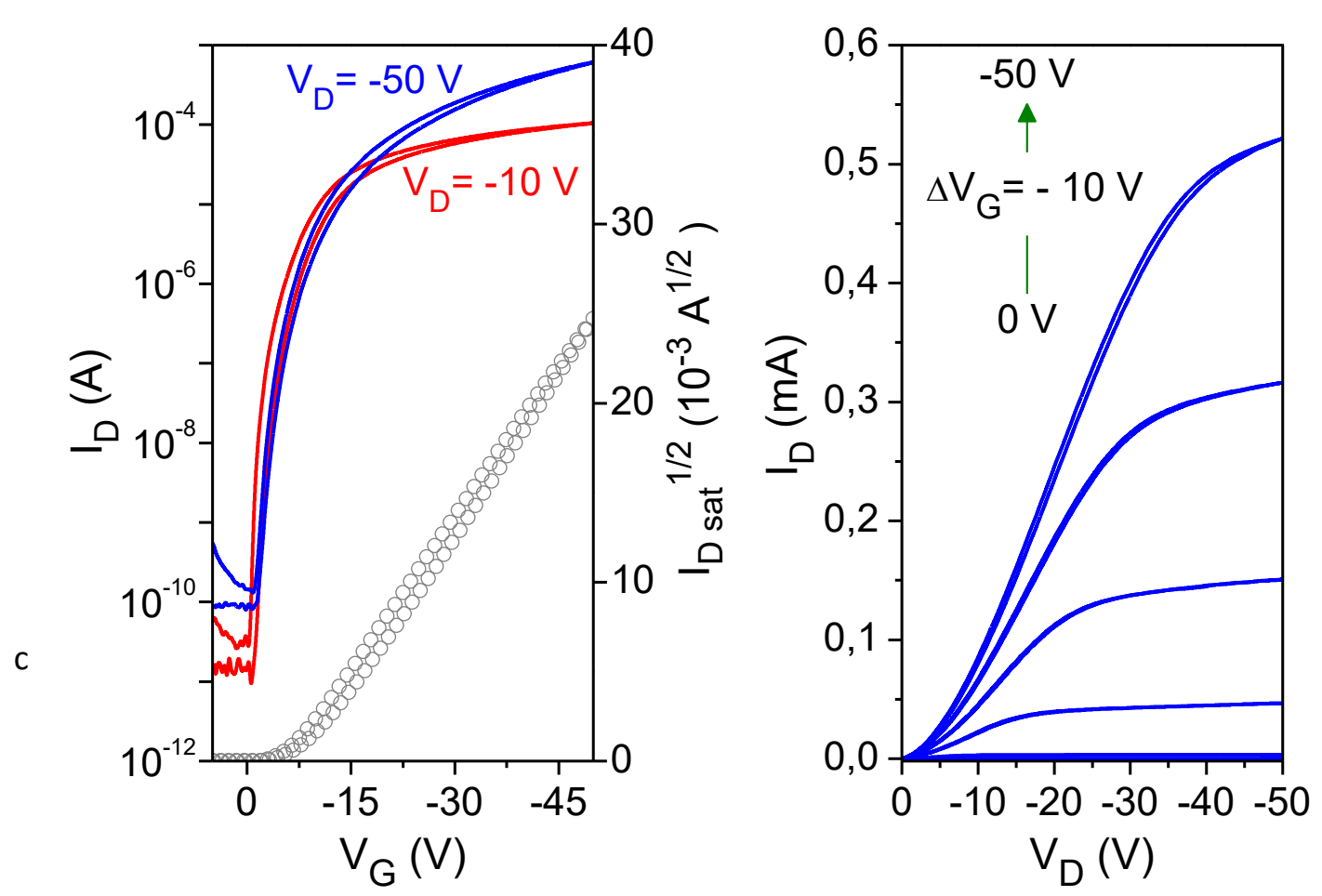

Figure 11. Transfer and output characteristics of a bottom-gate OTFT fabricated with molecules 2a. The transistor channel dimensions were $\mathrm{L}=50 \mu \mathrm{m}$ and $\mathrm{W}=1.5 \mathrm{~mm}$.
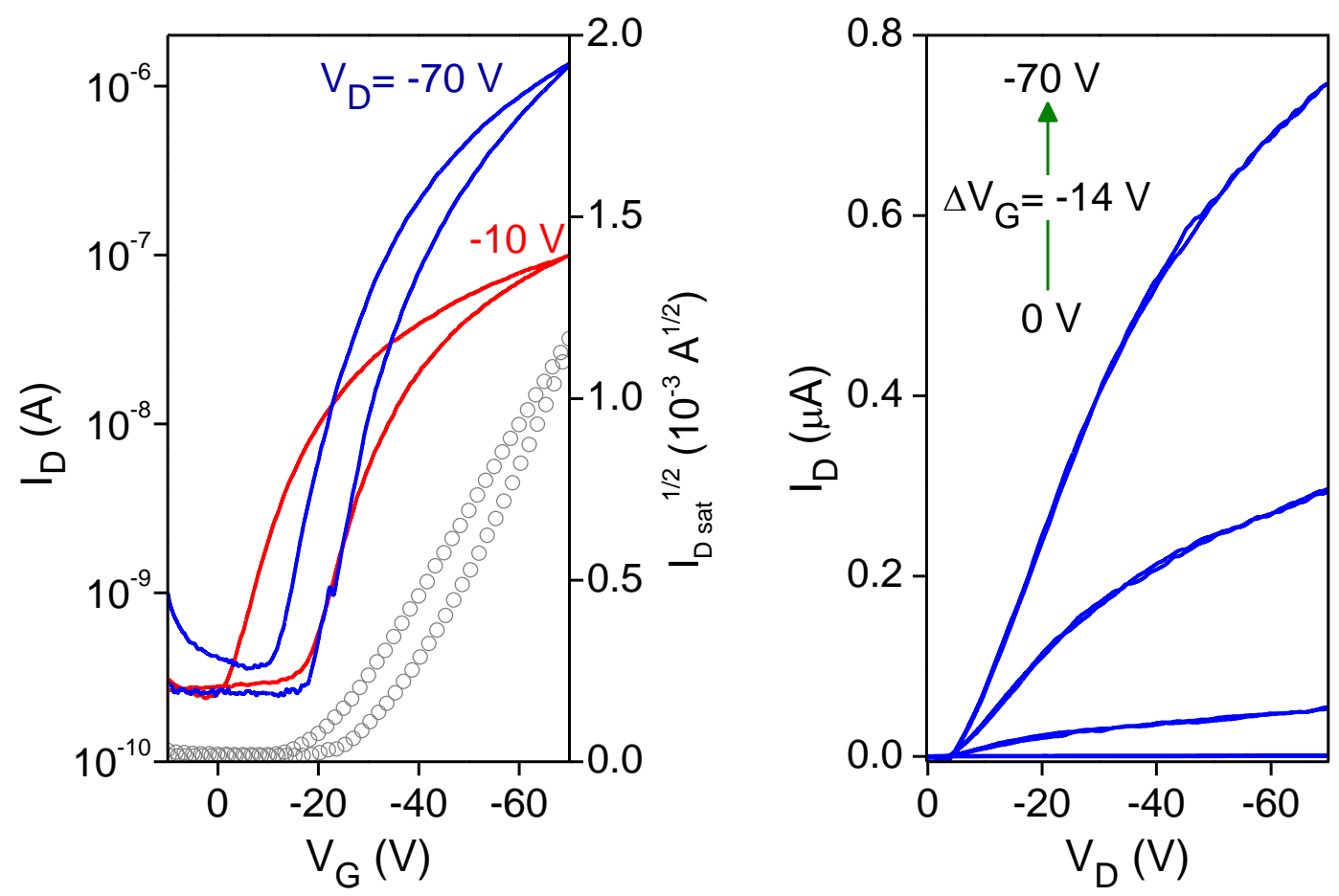

Figure 12. Transfer and output characteristics of a top-gate OTFT fabricated with molecules 3a. The transistor channel dimensions were $\mathrm{L}=30 \mu \mathrm{m}$ and $\mathrm{W}=1 \mathrm{~mm}$. 


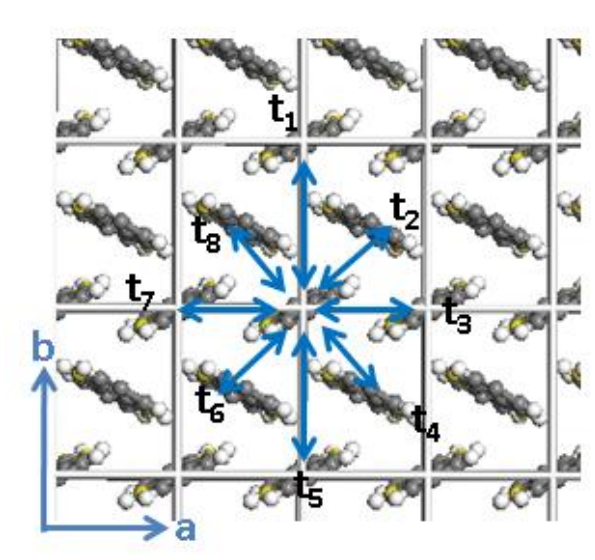

\begin{tabular}{|c|c|}
\hline & $\begin{array}{c}J_{\text {HOMO }} \\
(\mathrm{meV})\end{array}$ \\
\hline $\mathrm{t}_{1}$ & $\sim 0$ \\
\hline $\mathrm{t}_{2}$ & 12 \\
\hline $\mathrm{t}_{3}$ & 40 \\
\hline $\mathrm{t}_{4}$ & 12 \\
\hline $\mathrm{t}_{5}$ & $\sim 0$ \\
\hline $\mathrm{t}_{6}$ & 12 \\
\hline $\mathrm{t}_{7}$ & 40 \\
\hline $\mathrm{t}_{8}$ & 12 \\
\hline
\end{tabular}
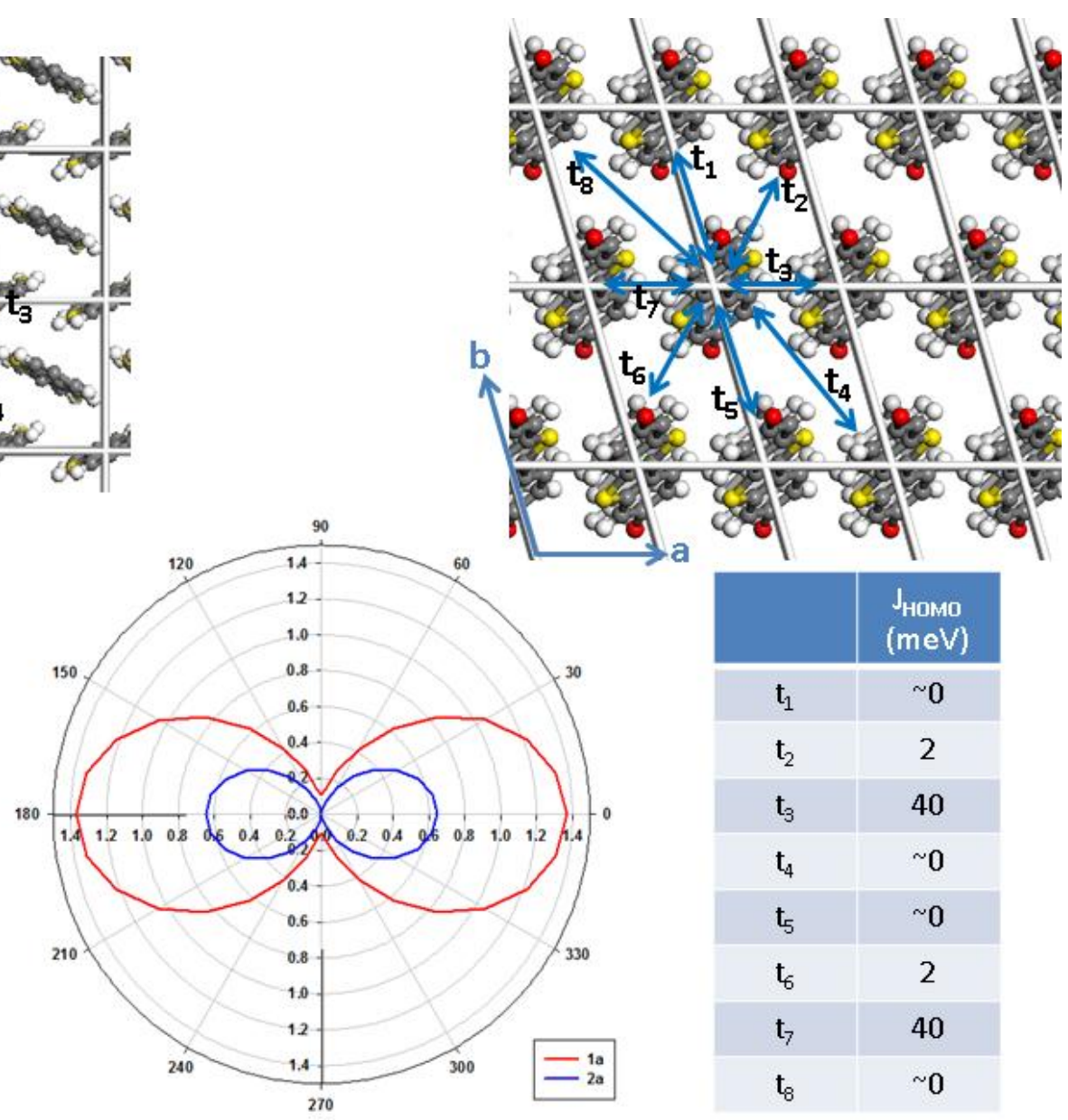

Figure 13. Representation of the packing of $\mathbf{1 a}$ (left) and 2a (right) as well as amplitude of their HOMO transfer integrals. Center: Anisotropy of the hole mobilities (in $\mathrm{cm}^{2} / \mathrm{Vs}$ ) in $\mathbf{1 a}$ (red) and $\mathbf{2 a}$ (blue), as calculated within a pure hopping regime. 

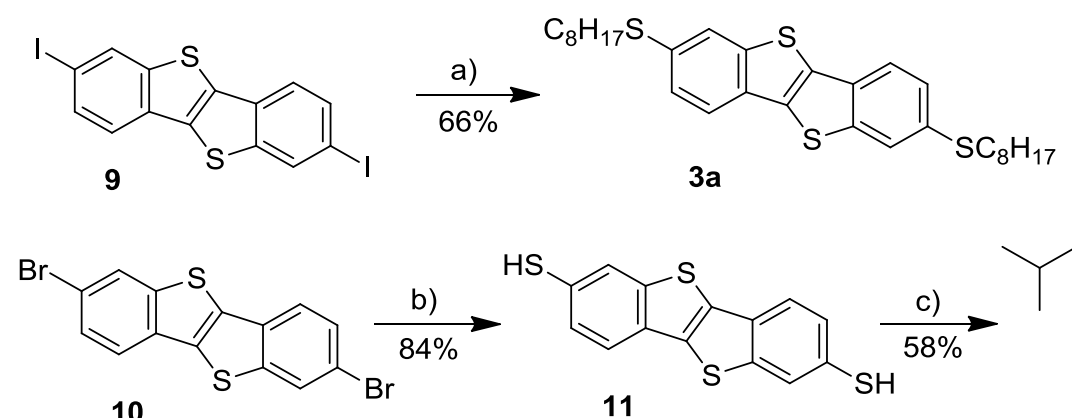

10
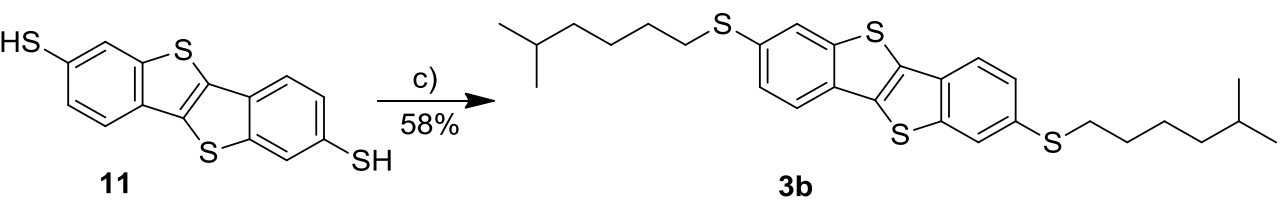

Scheme 1. Synthesis of 2,7-dialkylthio-[1]benzothieno[3,2-b][1]benzothiophenes. a) CuI, 1,10phenanthroline, $\mathrm{Cs}_{2} \mathrm{CO}_{3}$, octanethiol, $160{ }^{\circ} \mathrm{C}$; b) 1) NaSMe, DMA, $150{ }^{\circ} \mathrm{C}$. 2) $\mathrm{HCl}$; c) 1-Bromo-5methylhexane, $\mathrm{K}_{2} \mathrm{CO}_{3}$, DMF, $85^{\circ} \mathrm{C}$.

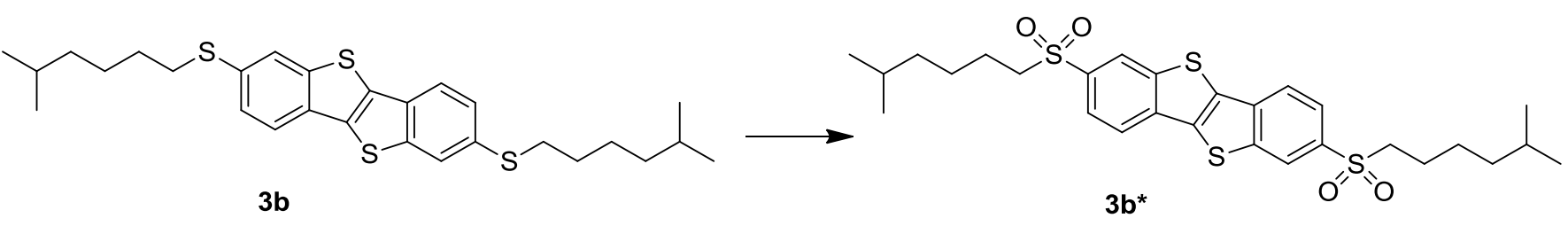

Scheme 2. Spontaneous oxidation of $\mathbf{3 b}$ into $\mathbf{3} \mathbf{b}^{*}$ upon crystallization in ambient atmosphere. 
Table 1. Synthesis of 2,7-dialkyloxy-[1]benzothieno[3,2-b][1]benzothiophenes. ${ }^{53}$<smiles>Ic1ccc2c(c1)sc1c3ccc(I)cc3sc21</smiles>

6

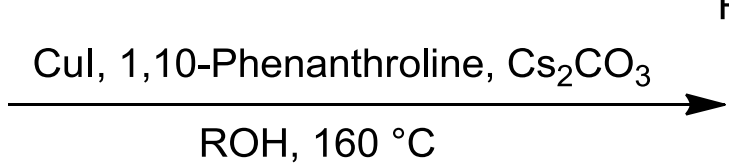

$\mathrm{ROH}, 160^{\circ} \mathrm{C}$

\begin{tabular}{|c|c|c|c|}
\hline Entry & ROH & 2,7-dialkyloxyBTBT & Yield [\%] \\
\hline I & 1-octanol & $\mathbf{2 a}$ & 70 \\
\hline II & 6-methyl-1-hexanol & $\mathbf{2 b}$ & 43 \\
\hline III & 7,7,8,8,8-pentafluoro-1-octanol & $\mathbf{2 c}$ & 48 \\
\hline
\end{tabular}

Table 2. Redox potentials, in $\mathrm{V}$ versus $\mathrm{Fc} / \mathrm{Fc}^{+}$, measured for the BTBT series together with the Brown coefficients corresponding to the substitution pattern. ${ }^{85}$

\begin{tabular}{|l|c|c|c|c|c|c|c|c|}
\hline & $\mathbf{1 a}$ & $\mathbf{2 a}$ & $\mathbf{3 a}$ & $\mathbf{4}$ & $\mathbf{5}$ & $\mathbf{6}$ & $\mathbf{7}$ & $\mathbf{8}$ \\
\hline$E_{1 / 2}^{o x 1}$ & 0.824 & 0.507 & 0.529 & 0.930 & 1.469 & 0.899 & 0.344 & 1.038 \\
\hline$E_{1 / 2}^{o x 2}$ & $\mathrm{n} / \mathrm{a}$ & 1.027 & 0.970 & $\mathrm{n} / \mathrm{a}$ & $\mathrm{n} / \mathrm{a}$ & $\mathrm{n} / \mathrm{a}$ & 1.069 & $\mathrm{n} / \mathrm{a}$ \\
\hline$\sum \sigma_{p}^{+}$ & -0.62 & -1.56 & -1.20 & -0.31 & 1.58 & -0.36 & -1.3 & 0 \\
\hline
\end{tabular}

Table 3. Experimental ionisation potentials of compounds 1a, 2a-c, and 3a-b.

\begin{tabular}{|l|c|c|c|c|c|c|}
\hline Ionisation Potentials (eV) $^{\text {a) }}$ & $\mathbf{1 a}$ & $\mathbf{2 a}$ & $\mathbf{2 b}$ & $\mathbf{2 c}$ & $\mathbf{3 a}$ & $\mathbf{3 b}$ \\
\hline IP (powder) & 5.35 & 5.71 & 5.87 & 5.99 & 5.40 & 5.72 \\
\hline IP (drop-casted films) & 5.38 & 5.39 & 5.90 & 5.99 & 5.60 & 5.63 \\
\hline IP (spin-coated films) & 5.35 & 5.42 & 5.90 & $\left.-{ }^{b}\right)$ & 5.57 & 5.63 \\
\hline
\end{tabular}

a) The error on IPs is $\pm 0.04 \mathrm{eV}$. ${ }^{\text {b) }}$ Measurement not possible due to significant background signal from the substrate as a consequence of low surface coverage. 
Table 4. Crystallographic data for compounds 2a-c. The data for $\mathbf{1 a}$ were acquired from the literature. ${ }^{68}$ Crystal data for $\mathbf{3} \mathbf{b}^{*}$ corresponds to the structure of the oxidised form of compound $\mathbf{3 b}$, as explained in the text.

\begin{tabular}{|c|c|c|c|c|c|}
\hline & $1 a^{68}$ & $2 \mathbf{a}$ & $2 \mathbf{b}$ & $2 c$ & $3 \mathbf{b}^{*}$ \\
\hline empirical formula & $\mathrm{C}_{30} \mathrm{H}_{40} \mathrm{~S}_{2}$ & $\mathrm{C}_{30} \mathrm{H}_{40} \mathrm{O}_{2} \mathrm{~S}_{2}$ & $\mathrm{C}_{28} \mathrm{H}_{36} \mathrm{O}_{2} \mathrm{~S}_{2}$ & $\mathrm{C}_{30} \mathrm{H}_{30} \mathrm{~F}_{10} \mathrm{O}_{2} \mathrm{~S}_{2}$ & $\mathrm{C}_{28} \mathrm{H}_{36} \mathrm{O}_{4} \mathrm{~S}_{4}$ \\
\hline molecular weight & 464.77 & 496.74 & 468.69 & 676.66 & 564.81 \\
\hline crystal system & monoclinic & triclinic & Orthorhombic & monoclinic & monoclinic \\
\hline space group & $\mathrm{P} 2_{1} / \mathrm{a}$ & $\mathrm{P}-1$ & $\mathrm{P} 2_{1} 2_{1} 2_{1}$ & $\mathrm{P} 2{ }_{1} / \mathrm{c}$ & $\mathrm{C} 2 / \mathrm{c}$ \\
\hline $\mathrm{a} / \AA$ & $5.927(7)$ & $5.5225(4)$ & $7.639(3)$ & $23.0898(13)$ & $49.296(2)$ \\
\hline $\mathrm{b} / \AA$ & $7.88(1)$ & $8.0712(4)$ & $7.759(3)$ & $5.6492(3)$ & $5.4166(3)$ \\
\hline $\mathrm{c} / \AA$ & $29.18(4)$ & $31.0578(15)$ & $42.556(17)$ & $11.3886(8)$ & $10.2355(6)$ \\
\hline$\alpha /{ }^{\circ}$ & - & $94.482(4)$ & - & - & - \\
\hline$\beta /{ }^{\circ}$ & $92.443(4)$ & 92.994(5) & - & $93.482(5)$ & $96.310(5)$ \\
\hline$\gamma /{ }^{\circ}$ & - & $105.696(5)$ & - & - & - \\
\hline volume $/ \AA^{3}$ & $1362(3)$ & $1324.76(13)$ & $2522.5(18)$ & $1482.77(15)$ & $2716.5(2)$ \\
\hline $\mathrm{Z}$ & 2 & 2 & 4 & 2 & 4 \\
\hline$\rho / \mathrm{g} / \mathrm{cm}^{3}$ & & 1.245 & 1.234 & 1.516 & 1.381 \\
\hline Temperature / K & 293 & 123 & $100(2)$ & 123 & 123 \\
\hline$\left(\mathrm{R}_{\text {int }}\right)$ unique & 0.077 & 0.0474 & 0.0459 & 0.0425 & 0.0299 \\
\hline reflections & 1268 & 5633 & 5690 & 3683 & 2706 \\
\hline final $R, \omega R 2$ & 0.070 & 0.0537 & 0.0489 & 0.0452 & 0.0333 \\
\hline$[\mathrm{I}>2 \sigma(\mathrm{I})]$ & 0.152 & 0.0918 & 0.1207 & 0.1025 & 0.0879 \\
\hline $\mathrm{R}, \omega \mathrm{R} 2$ & - & 0.0939 & 0.0511 & 0.0632 & 0.0360 \\
\hline (all data) & - & 0.1040 & 0.1232 & 0.1156 & 0.0912 \\
\hline Goof & 1.329 & 1.054 & 1.064 & 1.024 & 1.041 \\
\hline
\end{tabular}


Table 5. Intermolecular hydrogen bonds in the crystal structures of $\mathbf{2 a - c}$ and $\mathbf{3} \mathbf{b}^{*}$.

\begin{tabular}{|c|c|c|c|c|c|c|}
\hline & $\mathrm{D} \cdots \mathrm{A} / \mathrm{D}-\mathrm{H} \cdots \mathrm{A}(\AA)$ & $\mathrm{d}(\mathrm{D}-\mathrm{H})(\AA)$ & $\mathrm{d}(\mathrm{D}-\mathrm{A})(\AA)$ & $\mathrm{d}(\mathrm{H} \cdots \mathrm{A})(\AA)$ & $\mathrm{D}-\mathrm{H} \cdots \mathrm{A}\left({ }^{\circ}\right)$ & symmetry \\
\hline \multirow{2}{*}{$\mathbf{2 a}$} & $\mathrm{C} 24-\mathrm{H} 24 \mathrm{~B} \cdots \mathrm{Cg} 4$ & 0.98 & $3.671(2)$ & 2.78 & 150 & $-\mathrm{x},-1-\mathrm{y}, 1-\mathrm{z}$ \\
\cline { 2 - 7 } & $\mathrm{C} 25-\mathrm{H} 25 \mathrm{~A} \cdots \mathrm{Cg} 1$ & 0.98 & $3.654(2)$ & 2.79 & 146 & $-\mathrm{x},-\mathrm{y}, 1-\mathrm{z}$ \\
\hline \multirow{2}{*}{$\mathbf{2 b}$} & $\mathrm{C} 15-\mathrm{H} 15 \mathrm{~A} \cdots \mathrm{Cg} 4$ & 0.99 & $3.581(3)$ & 2.67 & 153 & $1 / 2+\mathrm{x},-1 / 2-\mathrm{y},-\mathrm{z}$ \\
\cline { 2 - 7 } & $\mathrm{C} 22-\mathrm{H} 22 \mathrm{~B} \cdots \mathrm{Cg} 3$ & 0.99 & $3.848(3)$ & 2.93 & 154 & $-1 / 2+\mathrm{x}, 1 / 2-\mathrm{y},-\mathrm{z}$ \\
\hline \multirow{2}{*}{$\mathbf{2 c}$} & $\mathrm{C} 8-\mathrm{H} 8 \mathrm{~B} \cdots \mathrm{Cg} 3$ & 0.99 & $3.668(2)$ & 2.85 & 140 & $\mathrm{x}, 1 / 2-\mathrm{y}, 1 / 2+\mathrm{z}$ \\
\hline \multirow{2}{*}{ 3b* } & $\mathrm{C} 6-\mathrm{H} 6 \cdots \mathrm{O} 2$ & 0.95 & 3.423 & 2.56 & 152 & $\mathrm{x},-\mathrm{y},-1 / 2+\mathrm{z}$ \\
\cline { 2 - 7 } & $\mathrm{C} 8-\mathrm{H} 8 \mathrm{~A} \cdots \mathrm{O} 1$ & 0.99 & 3.469 & 2.60 & 147 & $\mathrm{x}, 1+\mathrm{y}, \mathrm{z}$ \\
\hline
\end{tabular}

where $\mathrm{Cg} 1$ is the centroid of the ring formed by atoms $\mathrm{S} 1, \mathrm{C} 2-\mathrm{C} 4$ in $\mathbf{2 a} ; \mathrm{Cg} 3$ is the centroid of the ring formed by atoms $\mathrm{C} 3-\mathrm{C} 8$ in $\mathbf{2 b}$ and atoms $\mathrm{C} 2-\mathrm{C} 7$ in $\mathbf{2 c}$. $\mathrm{Cg} 4$ is the centroid of the ring formed by atoms C9-C14 in $\mathbf{2 a}$ and $\mathbf{2 b}$.

Table 6. TGA weight loss onset temperatures and DSC transition temperatures with their associated enthalpies

\begin{tabular}{|l|c|c|c|c|c|c|c|c|}
\hline \multirow{2}{*}{ Comp. } & \multirow{2}{*}{$\mathrm{TGA}^{\circ}$} & \multicolumn{7}{|c|}{$\mathrm{DSC} \mathrm{T}_{\text {onset }}\left({ }^{\circ} \mathrm{C}\right) / \Delta \mathrm{H}\left(\mathrm{kJ} \mathrm{mol}^{-1}\right)$} \\
\cline { 3 - 9 } & $\mathrm{T}_{\text {onset }}\left({ }^{\circ} \mathrm{C}\right)$ & $\mathrm{T}_{\mathrm{Cr}-\mathrm{Cr}}$ & $\Delta \mathrm{H}_{\mathrm{Cr}-\mathrm{Cr}}$ & $\mathrm{T}_{\mathrm{Cr}-\mathrm{CL}}$ & $\Delta \mathrm{H}_{\mathrm{Cr}-\mathrm{CL}}$ & $\mathrm{T}_{\mathrm{CL}-\mathrm{L}}$ & $\mathrm{T}_{\mathrm{Cr}-\mathrm{L}}$ & $\Delta \mathrm{H}_{\mathrm{CL}-\mathrm{L} / \mathrm{Cr}-\mathrm{L}}$ \\
\hline $\mathbf{1 a}$ & 341 & - & - & 109.1 & 32.3 & 125.6 & - & 7.5 \\
\hline $\mathbf{2 a}$ & 385 & 90.7 & 6.4 & 159.3 & 15.8 & 173.1 & - & 9.4 \\
\hline $\mathbf{2 b}$ & 342 & 108.8 & 1.1 & - & - & - & 172.7 & 33.3 \\
\hline $\mathbf{2 c}$ & 349 & 134.2 & 6.8 & 148.7 & 32.1 & - & 205.7 & 8.0 \\
\hline $\mathbf{3 a}^{\mathrm{I}}$ & \multirow{2}{*}{361} & 109.2 & 3.8 & - & - & - & 162.1 & 29.5 \\
\hline $\mathbf{3 a}^{\mathrm{I}}$ & & - & - & - & - & - & 161.8 & 29.3 \\
\hline $\mathbf{3 b}$ & 328 & 163.2 & 4.9 & - & - & - & 163.5 & 36.9 \\
\hline
\end{tabular}

${ }^{\mathrm{I}} 1^{\text {st }}$ heating-cooling cycle, ${ }^{\text {II }} 2^{\text {nd }}$ heating-cooling cycle

Table 7. Device parameters of best-performing TFTs fabricated with molecules 1a, 2a, and 3a.

\begin{tabular}{|c|c|c|c|c|}
\hline molecule & $\mu_{\text {saturation }}\left(\mathrm{cm}^{2} / \mathrm{Vs}\right)$ & $\mathrm{I}_{\mathrm{on}} / \mathrm{I}_{\mathrm{off}}$ & $\mathrm{V}_{\mathrm{T}}(\mathrm{V})$ & subthreshold slope $(\mathrm{V} / \mathrm{dec})$ \\
\hline 1a (Bottom Gate) & 4 & $10^{6}$ & -5 & 1.5 \\
\hline 2a (Bottom Gate) & 0.5 & $10^{5}$ & -17 & 5 \\
\hline 3a (Top Gate) & 0.05 & $3 \times 10^{3}$ & -20 & 7.5 \\
\hline
\end{tabular}

